\title{
All-Sky Radiance Assimilation of ATMS in HWRF: A Demonstration Study
}

\author{
Ting-CHI Wu, Milija ZuPanski, AND LeWIS D. GRASSO \\ Cooperative Institute for Research in the Atmosphere, Colorado State University, Fort Collins, Colorado \\ CHRISTIAN D. KUMMEROW \\ Cooperative Institute for Research in the Atmosphere, and Department of Atmospheric \\ Science, Colorado State University, Fort Collins, Colorado \\ SID-AHMED BOUKABARA \\ NOAA/NESDIS Center for Satellite Applications and Research, College Park, Maryland
}

(Manuscript received 9 November 2017, in final form 11 October 2018)

\begin{abstract}
Satellite all-sky radiances from the Advanced Technology Microwave Sounder (ATMS) are assimilated into the Hurricane Weather Research and Forecasting (HWRF) Model using the hybrid Gridpoint Statistical Interpolation analysis system (GSI). To extend the all-sky capability recently developed for global applications to HWRF, some modifications in HWRF and GSI are facilitated. In particular, total condensate is added as a control variable, and six distinct hydrometeor habits are added as state variables in hybrid GSI within HWRF. That is, clear-sky together with cloudy and precipitation-affected satellite pixels are assimilated using the Community Radiative Transfer Model (CRTM) as a forward operator that includes hydrometeor information and Jacobians with respect to hydrometeor variables. A single case study with the 2014 Atlantic storm Hurricane Cristobal is used to demonstrate the methodology of extending the global all-sky capability to HWRF due to ATMS data availability. Two data assimilation experiments are carried out. One experiment uses the operational configuration and assimilates ATMS radiances under the clear-sky condition, and the other experiment uses the modified HWRF system and assimilates ATMS radiances under the all-sky condition with the inclusion of total condensate update and cycling. Observed and synthetic Geostationary Operational Environmental Satellite (GOES)-13 data along with Global Precipitation Measurement Mission (GPM) Microwave Imager (GMI) data from the two experiments are used to show that the experiment with all-sky ATMS radiances assimilation has cloud signatures that are supported by observations. In contrast, there is lack of clouds in the initial state that led to a noticeable lag of cloud development in the experiment that assimilates clear-sky radiances.
\end{abstract}

\section{Introduction}

Assimilation of satellite radiances is part of the operational routine in many numerical weather prediction (NWP) centers. Because of the difficulties in handling cloudy and precipitation-affected satellite pixels in data assimilation (Errico et al. 2007; Zupanski 2013), many NWP centers started with assimilation of satellite clearsky radiances (the process of excluding cloudy and precipitation-affected satellite pixels over both land and ocean). Over the past several years, many NWP centers have participated in steps to improve assimilation of

Corresponding author: T.-C. Wu, ting-chi.wu@colostate.edu satellite all-sky radiances (the process of including cloudy and precipitation-affected satellite pixels over both land and the ocean; Geer et al. 2018). Among these are the National Centers for Environmental Prediction (NCEP; Zhu et al. 2014, 2016), the European Centre for Medium-Range Weather Forecasts (ECMWF; Bauer et al. 2010; Geer et al. 2010; Bauer et al. 2011a,b), Météo-France (Guidard et al. 2011; Guerbette et al. 2016), the Japan Meteorological Agency (JMA; Okamoto 2013), the Met Office (Renshaw and Francis 2011), and Environmental and Climate Change Canada (Heilliette and Garand 2007; Heilliette et al. 2013). As an example of progress, all-sky microwave radiances over ocean were first assimilated by the 4DVar system developed at 
ECMWF during 2009. Although individual hydrometeor habits were not considered as control variables in the ECMWF system, they were diagnosed during the forward integration process. Unlike the approach of ECMWF, NCEP uses the Gridpoint Statistical Interpolation analysis system (GSI; Wu et al. 2002; Kleist et al. 2009), which evolved from Spectral Statistical Interpolation (SSI; Parrish and Derber 1992) and employs total condensate mass in addition to other variables, which serve as control variables. In particular, total condensate mass is partitioned into cloud water $\left(q_{l}\right)$ and cloud ice $\left(q_{i}\right)$, both of which are treated as state variables and are used by the Community Radiative Transfer Model (CRTM; Han et al. 2006; Weng and Liu 2003; Weng 2007) to compute top-of-the-atmosphere radiances for the Global Forecast System (GFS). Specifically, ocean-only, clear, and nonprecipitating cloudy affected satellite radiances measured by the polar-orbiting Advanced Microwave Sounding Unit-A (AMSU-A) are assimilated in GFS using GSI (Zhu et al. 2016). The inclusion of nonprecipitating cloudy affected radiances represents a significant step toward all-sky assimilation. However, implementation on a regional scale has yet to be done.

Currently, the National Oceanic and Atmospheric Administration (NOAA) operational Hurricane Weather Research and Forecasting (HWRF; Tallapragada et al. 2015) Model assimilates satellite radiances only with clear-sky pixels. Subsequently, microphysical habits are not treated as control variables and therefore are not updated during the data assimilation process. As pointed out by Huang (1996), such inconsistent treatment of microphysical and other thermodynamic variables may create potential imbalances in a resulting analysis field. In addition, use of only clear-sky radiances potentially limits any benefits of cloudy and precipitation-affected radiances.

A next step in the progression from clear-sky to allsky radiance assimilation on the regional scale is the inclusion of cloudy and precipitation-affected satellite pixels. In a recent study by Yang et al. (2016), the impact of assimilating all-sky radiances from the Advanced Microwave Scanning Radiometer 2 (AMSR2) on the analysis and forecast of Hurricane Sandy (2012) was examined using the Advanced Research version of WRF (ARW) Model coupled with the WRF Data Assimilation (WRFDA) 3DVar system. Compared to their clear-sky experiment, ocean-only all-sky pixels were assimilated in their all-sky experiment by employing total water as an additional control variable, as opposed to humidity. An overall improvement in track, intensity, and precipitation forecast was achieved in the all-sky experiment. In addition, Zhang et al. (2013) assimilated cloudy affected radiances from AMSU-A into the inner core of Hurricane Danielle, which occurred in 2010, using HWRF coupled to the maximum likelihood ensemble filter (Zupanski 2005). Total condensate mass was treated as a control variable in their all-sky experiment, which is similar to Zhu et al. (2016). A measureable positive impact on the intensity prediction of the hurricane was identified. Also, a more realistic hydrometeor structure of Hurricane Danielle was achieved due to the use of flow-dependent multivariate covariance. While the abovementioned work focused on the assimilation of all-sky radiances from microwave sensors, recent studies by Zhang et al. (2016) and Minamide and Zhang $(2017,2018)$ extended the all-sky efforts to infrared radiances from the Advanced Himawari Imager on the Himawari-8 satellite and the Advanced Baseline Imager on the Geostationary Operational Environmental Satellite (GOES)-16 satellite.

Advanced Technology Microwave Sounder (ATMS) on board the nonoperational Suomi National PolarOrbiting Partnership (SNPP) satellite is used in this study in preparation for a new ATMS on board the nowoperational NOAA-20. To assimilate all-sky ATMS radiances into HWRF, the GSI all-sky capability for GFS is adapted in HWRF for the study herein. As a reminder, Zhu et al. (2016) developed a technique to enhance clear-sky assimilation by including nonprecipitating cloudy affected pixels for ocean-only scenes from AMSU-A. The current study extends Zhu et al. (2016) in three ways. First, clear-sky assimilation is enhanced through the inclusion of both nonprecipitating and precipitating cloudy affected pixels for ocean-only scenes using ATMS data. Second, the global-scale (GFS) technique is applied to the innermost domain of a regional-scale model (HWRF). Finally, following Wu and Zupanski (2017), total condensate mass is partitioned into six hydrometeor habits: cloud water $\left(q_{l}\right)$, rain $\left(q_{r}\right)$, cloud ice $\left(q_{i}\right)$, snow $\left(q_{s}\right)$, graupel $\left(q_{g}\right)$, and hail $\left(q_{h}\right)$. Each of the six distinct habits is included within an existing group of state variables for the current study. An additional relevant detail is as follows: observation errors for all-sky ATMS radiances are computed using the "symmetric error model" (Geer and Bauer 2011) with the HWRF first guess, which is the 6-h forecast from a previous cycle.

This study focuses on results obtained from HWRF data assimilation experiments of the 2014 Atlantic Hurricane Cristobal. The methodology for assimilating ATMS radiances in HWRF with GSI is discussed in section 2. Case study description and HWRF data assimilation and forecast experimental design are presented in section 3. Results from the GSI assimilation experiments are contained in section 4 , while section 5 details results from the forecasts. Finally, section 6 provides summary, discussions, and future directions. 


\section{Methodology for assimilating all-sky radiances in HWRF}

\section{a. Operational HWRF 2015 implementation}

The HWRF v3.7a release (Tallapragada et al. 2015) is employed in this study. As a numerical weather prediction system, HWRF is composed of three major components:

1) An initialization component that includes a preprocessing step to initialize all five domains with the use of GFS and Global Data Assimilation System (GDAS; Kleist et al. 2009) data, a vortex initialization procedure and a data assimilation system that is based on the GSI.

2) A forecasting component that is composed of the Nonhydrostatic Mesoscale Model (NMM; Janjic 2003) dynamical core of WRF and the Princeton Ocean Model for Tropical Cyclones (POM-TC; Yablonsky et al. 2015) model combined by the NCEP coupler.

3) A postprocessing package that includes the Unified Post-Processing (UPP) and Geophysical Fluid Dynamics Laboratory (GFDL) vortex tracker (Marchok 2002).

In version 3.7a of HWRF, the NMM core is configured with a total of three forecast domains and two data assimilation domains (Fig. 1). Horizontal grid spacing in each of the three forecast domains is 18,6 , and $2 \mathrm{~km}$ in $\mathrm{d} 01, \mathrm{~d} 02$, and $\mathrm{d} 03$, respectively. The areal extent of each domain is $5200 \mathrm{~km} \times 5200 \mathrm{~km}$ in d01, $850 \mathrm{~km} \times 850 \mathrm{~km}$ in $\mathrm{d} 02$, and $530 \mathrm{~km} \times 530 \mathrm{~km}$ in $\mathrm{d} 03$. All grids have 61 vertical levels, and the model top is set to $2 \mathrm{hPa}$. Both $\mathrm{d} 02$ and $\mathrm{d} 03$ are not only two-way nested grids, but also movable based on the location of the simulated hurricane center. Data assimilation occurs on two grids called ghost-d02 and ghost-d03. Ghost-d02 and ghost-d03 allow the possibility of more observations to be assimilated because these two domains extend over a larger geographic region, compared to $\mathrm{d} 02$ and $\mathrm{d} 03$. Specifically, the areal extent of ghost-d02 is $1700 \mathrm{~km} \times$ $1700 \mathrm{~km}$, and that of ghost-d03 is $870 \mathrm{~km} \times 870 \mathrm{~km}$. As a reminder, d01-03 are used during the forecast portion of HWRF, and ghost-d02-03 are only used during the data assimilation portion of HWRF.

The HWRF data assimilation component utilizes GSI with a regional hybrid ensemble-3DVar data assimilation scheme (Wang 2010), in which hybrid refers to the use of a combination of static background error covariance and a flow-dependent background error covariance estimated from ensemble forecasts. In operational HWRF, the weight given to the static component is $20 \%$, and the weight given to the ensemble component is $80 \%$. In most cases, the ensemble component of hybrid GSI employs an 80-member ensemble forecast from the GFS

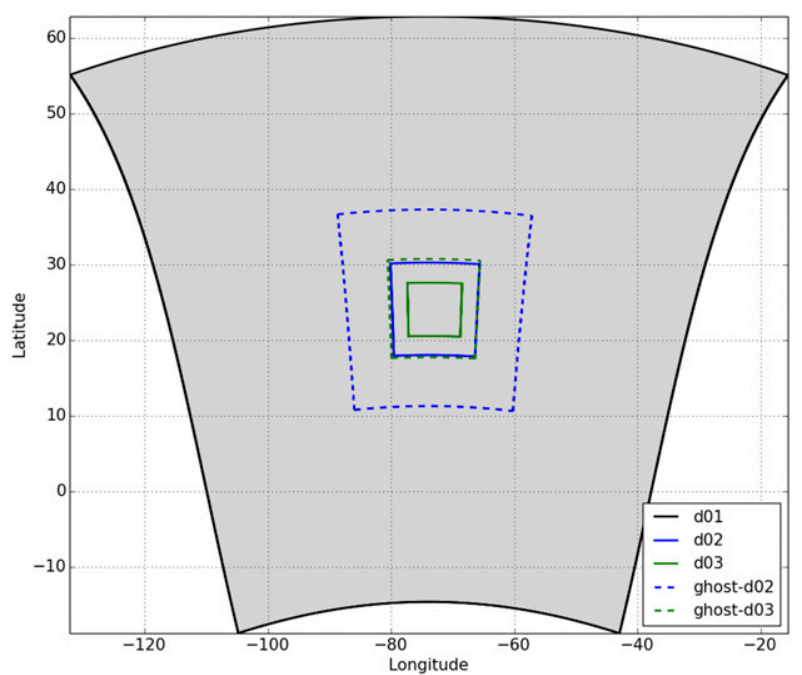

FIG. 1. HWRF forecast domains, as indicated by d01 (black line), d02 (solid blue line), and d03 (solid green line), and HWRF data assimilation domains, as indicated by ghost-d02 (dashed blue line) and ghost-d03 (dashed green line).

global hybrid ensemble Kalman filter (EnKF)-3DVar system (Wang et al. 2013), which has recently been upgraded to a hybrid 4DEnVar system (Wang and Lei 2014; Kleist and Ide 2015). However, when NOAA P-3 tail Doppler radar (TDR) data are available during a storm of interest, hybrid GSI will use an HWRF-based ensemble (Lu et al. 2017). The HWRF-based ensemble is a 40-member high-resolution HWRF ensemble forecast initialized from the GFS analysis ensemble. Since the capability to use an HWRF-based ensemble is not supported as part of the v3.7a version of HWRF, which is employed in this current study, the GFS ensemble is used instead. Compared to using the GFS ensemble, there exist many benefits of using an HWRF-based ensemble. A recent study by Pu et al. (2016) has shown that the well-known vortex spindown problem in HWRF may be mitigated when a high-resolution native ensemble is used. Furthermore, covariance localization is applied to the ensemble component of the background error covariance. The horizontal localization length for ghost-d02 and ghost-d03 is 300 and $150 \mathrm{~km}$, respectively. The vertical localization length for both ghost-d02 and ghost-d03 is 0.5 in the unit of $\ln (p)$, where $p$ is in cbar. Finally, the hybrid GSI employed by HWRF uses two outer loops, and each has 50 inner loops. More details regarding the configuration of GSI within the HWRF system can be found in Tallapragada et al. (2015).

After data assimilation, the resulting analyses in ghost-d02 and ghost-d03, together with d01, are merged to provide initial conditions for $\mathrm{d} 01, \mathrm{~d} 02$, and $\mathrm{d} 03$. Within the so-called merge step, a blending procedure is 
used to avoid possible imbalances induced by data assimilation in the inner-core region. The blending procedure acts to remove analysis increments (analysis minus background) within $150-\mathrm{km}$ radius from the hurricane center and below $400 \mathrm{hPa}$. From a 150 - to a $300-\mathrm{km}$ radius, analysis and background are blended. However, the blending procedure is not used in this current study (see section 3c).

\section{b. Preparation of the background of cloud microphysical variables}

Among all the HWRF physics packages, the microphysics scheme is most directly related to the assimilation of all-sky radiances. The Ferrier-Aligo microphysics scheme (Aligo et al. 2014) employed by HWRF predicts changes in water vapor $\left(q_{v}\right)$ and total condensate (CWM). From CWM, individual hydrometeor habits-cloud water $\left(q_{l}\right)$, rain $\left(q_{r}\right)$, cloud ice $\left(q_{i}\right)$, snow $\left(q_{s}\right)$, graupel $\left(q_{g}\right)$, and hail $\left(q_{h}\right)$ - are diagnosed with the use of prognostic partition parameters that include fraction of ice $\left(F_{-}\right.$ICE), fraction of rain $\left(\mathrm{F} \_\right.$RAIN), and value of the riming rate (F_RIMEF).

Currently, however, HWRF is designed for clear-sky radiance assimilation because there is no preparation of cloud microphysical variables for a background field. Before the GSI data assimilation procedure, CWM and its partition parameters are excluded from the location-, intensity-, and size-correction procedures during the vortex initialization. As a consequence, zero values of total condensate and partition parameters are present in a background field that is used by hybrid GSI. In addition, there is no update of cloud microphysical variables during the hybrid GSI data assimilation procedure. As such, cloudy and precipitation-affected satellite pixels (ocean-only scenes) could not be directly assimilated in HWRF.

To extend the current clear-sky approach to an all-sky approach, several new procedures are required. Three distinct procedures are now discussed. First, values of CWM, F_ICE, F_RAIN, and F_RIMEF are established in the background (using the same fields in the forecasts from a previous HWRF cycle) to replace preexisting zeros prior to the hybrid GSI data assimilation. Second, Zhu et al. (2016) upgraded GSI to have the ability to assimilate all-sky microwave radiances with two restrictions; ocean-only scenes and nonprecipitating clouds. Because of the restrictions, the phrase quasi-all-sky is used following Grasso et al. (2018). For the study herein, modifications are made to enhance the existing quasi-allsky radiance assimilation in GSI. Following Zhu et al. (2016), CWM is added to the current set of GSI control variables for HWRF. In the study herein, the number of habits was extended to six individual hydrometeor species $\left(q_{l}, q_{r}, q_{i}, q_{s}, q_{g}\right.$, and $\left.q_{h}\right)$. Like in Zhu et al. (2016), $5 \%$ of the value of CWM from the first guess was used to specify the background error variance for the static component. Finally, the GSI code is modified to include both the tangent linear and the adjoint parts of the partitioning in the minimization process. In particular, a partition formula based on the Ferrier-Aligo microphysics scheme, embedded in GSI, to partition CWM into individual hydrometeors with F_ICE, F_RAIN, and F_RIMEF is used. For a more detailed description regarding the above procedures, interested readers may refer to $\mathrm{Wu}$ and Zupanski (2017). The abovementioned procedures facilitate the HWRF capability to cycle (via preparation of a background field with cloud microphysical variables from a previous cycle) and update (through all-sky radiance assimilation) cloud microphysical variables.

\section{c. All-sky ATMS radiances}

ATMS is an advanced microwave sounder on board both the $S N P P$ and $N O A A-20$ satellites. In this study, ATMS on board the nonoperational $S N P P$ satellite is used. Similar to its two predecessors, AMSU-A and the Microwave Humidity Sounder (MHS), ATMS provides observations of the surface and atmosphere of Earth. ATMS has 22 channels with frequencies ranging from 23.8 to $183.31 \mathrm{GHz}$. Channels 1-16 have frequencies ranging from 23.8 to $87.9 \mathrm{GHz}$ and are primarily used for temperature soundings. In contrast, channels 17-22 have frequencies ranging from 166.31 to $183.31 \mathrm{GHz}$ and are primarily used for water vapor soundings. In particular, channels 1-16 on ATMS are similar to those of AMSU-A; likewise, channels 17-22 are similar to those on MHS. Ocean-only ATMS clear-sky radiances are routinely assimilated in the ghost-d02 of HWRF along with clear-sky satellite radiances from other instruments. To move beyond the current assimilation of clear-sky radiances, ATMS all-sky radiances from channels 1-4, 7-9, and 16 over the oceans are included in the assimilation step of HWRF. These channels were selected to provide information on temperature, moisture, and precipitationsized particles interior to clouds that are relevant for hurricanes. Channels 1 and 2 are sensitive to liquid droplets. The temperature/oxygen channels 7-9 provide information about the warm core of hurricanes. In addition, the use of channel 16 helps identify the location of the deepest convection through a scattering signal from precipitation-sized ice particles (Table 1).

\section{d. Assimilation of ATMS all-sky radiances}

\section{1) OBSERVATION ERROR ASSIGNMENT}

While a single value observation error is often used in clear-sky radiance assimilation, the "symmetric error model" (Geer and Bauer 2011) is commonly used to model observation errors in all-sky condition. This method 
TABLE 1. Spectrally dependent thresholds that are used by the symmetric observation error model to assign errors for the selected ATMS channels under all-sky conditions.

\begin{tabular}{|c|c|c|c|c|}
\hline $\begin{array}{l}\text { Channel and central } \\
\text { frequency }(\mathrm{GHz})\end{array}$ & $C_{\mathrm{clr}}\left(\mathrm{kg} \mathrm{m}^{-2}\right)$ & $C_{\text {cld }}\left(\mathrm{kg} \mathrm{m}^{-2}\right)$ & $e_{\mathrm{clr}}(\mathrm{K})$ & $e_{\mathrm{cld}}(\mathrm{K})$ \\
\hline $1(23.8)$ & 0.05 & 0.35 & 3.5 & 25 \\
\hline $2(31.4)$ & 0.04 & 0.37 & 2 & 40 \\
\hline $3(50.3)$ & 0.03 & 0.35 & 2 & 15 \\
\hline $4(51.76)$ & 0.03 & 0.32 & 1.6 & 8 \\
\hline $7(54.40)$ & 0.1 & 0.6 & 0.2 & 1 \\
\hline $8(54.90)$ & 0.3 & 0.6 & 0.23 & 0.5 \\
\hline $9(55.5)$ & 0.3 & 0.6 & 0.17 & 0.3 \\
\hline $16(87.9)$ & 0.04 & 0.45 & 2.6 & 20 \\
\hline
\end{tabular}

creates an approximate model for observation error by fitting the standard deviation of first guess departures of radiances with the averaged/symmetric "cloud amount" from the first guess and the observation. Following Zhu et al. (2016), cloud liquid water (CLW; $\mathrm{kg} \mathrm{m}^{-2}$ ) is used to represent "cloud amount," and CLW is calculated using the retrieval formula proposed by Grody et al. (2001):

$$
\begin{aligned}
\mathrm{CLW}= & \cos \theta\left\{c_{0}+c_{1} \ln \left[T_{s}-T_{b}(\operatorname{ch} 1)\right]\right. \\
& \left.+c_{2} \ln \left[T_{s}-T_{b}(\operatorname{ch} 2)\right]\right\},
\end{aligned}
$$

where the constant $c_{0}$ is calculated as $c_{0}=8.24-(2.622-$ $1.846 \cos \theta) \cos \theta, c_{1}=0.754, c_{2}=-2.265, \theta$ is the satellite

zenith angle, $T_{s}$ is sea surface temperature and is set to $285 \mathrm{~K}$, and $T_{b}(\operatorname{ch} 1)$ and $T_{b}(\mathrm{ch} 2)$ are brightness temperatures for ATMS channels $1(23.8 \mathrm{GHz})$ and 2 (31.4 GHz), respectively. Using Eq. (1), one can compute $\mathrm{CLW}^{\mathrm{fg}}$ from the first guess (fg) brightness temperatures and $\mathrm{CLW}^{\text {obs }}$ from the observed (obs) brightness temperatures (Figs. 2a,b); hence, the averaged (avg) cloud amount is then defined as $\mathrm{CLW}^{\mathrm{avg}}=0.5\left(\mathrm{CLW}^{\mathrm{fg}}+\right.$ $\mathrm{CLW}^{\mathrm{obs}}$ ), which is illustrated in Fig. 2c.

The symmetric observation error $e$ is then described as a piecewise linear fit of $\mathrm{CLW}^{\mathrm{avg}}$ to the standard deviation of first guess departure of ATMS data and can be expressed by

$$
e=\left\{\begin{array}{lll}
e_{\mathrm{clr}} & \text { if } \quad \mathrm{CLW}^{\mathrm{avg}} \leq C_{\mathrm{clr}} \\
e_{\mathrm{clr}}+\frac{e_{\mathrm{cld}}-e_{\mathrm{clr}}}{C_{\mathrm{cld}}-C_{\mathrm{clr}}}\left(\mathrm{CLW}^{\mathrm{avg}}-C_{\mathrm{clr}}\right) & \text { if } \quad C_{\mathrm{clr}}<\mathrm{CLW}^{\mathrm{avg}}<C_{\mathrm{cld}}, \\
e_{\mathrm{cld}} & \text { if } \quad \mathrm{CLW}^{\mathrm{avg}} \geq C_{\mathrm{cld}}
\end{array}\right.
$$

where $e_{\text {clr }}$ is observation error under clear-sky condition, which is defined by a spectrally dependent threshold $C_{\text {clr }}$. Similarly, $e_{\text {cld }}$ is observation error under cloudy condition, defined by a spectrally dependent threshold $C_{\text {cld }}$. Finally, an example of symmetric observation errors for ATMS channel 2 at the analysis cycle, valid at 1800 UTC 26 August during Hurricane Cristobal, is shown in Fig. 2d.

Following Eq. (2), the symmetric observation error model for ATMS channel 2 is shown in Fig. 3 (see Table 2 for the nine HWRF first guesses from four 2014 Atlantic hurricanes). Although a relatively small amount of data is used in Fig. 3, results on the regional scale (HWRF) are qualitatively similar to those on the global scale [GFS; see Fig. 1 in Zhu et al. (2016)]. Values for $e_{\mathrm{clr}}$ and $e_{\mathrm{cld}}$ as well as thresholds for $C_{\mathrm{clr}}$ and $C_{\mathrm{cld}}$ for the ATMS channels $1-4,7-9$, and 16 are also listed in Table 1.

\section{2) PARTICLE SIZES FOR CRTM}

The CRTM is used within GSI as the forward operator for satellite radiances to compute top-of-the-atmosphere radiances for any given HWRF output. As a reminder, $\mathrm{CWM}$ is the prognostic variable in the Ferrier-Aligo microphysics. In order for the microphysics to communicate with the CRTM, CWM is partitioned into individual hydrometeor mass mixing ratio, and particle size (effective radius; $\mu \mathrm{m}$ ) is computed based on the FerrierAligo microphysical scheme within GSI. Both the mass mixing ratio and particle size of each of the six habits are then passed into the CRTM. Particle size is used by the CRTM to acquire optical properties-extinction, singlescattering albedo, and Legendre coefficients-from a predefined lookup table. The result of CRTM computation is top-of-the-atmosphere radiances for HWRF. A discussion about the partition of the mass of hydrometeor habits from CWM, based on the Ferrier-Aligo 
a) CLWobs

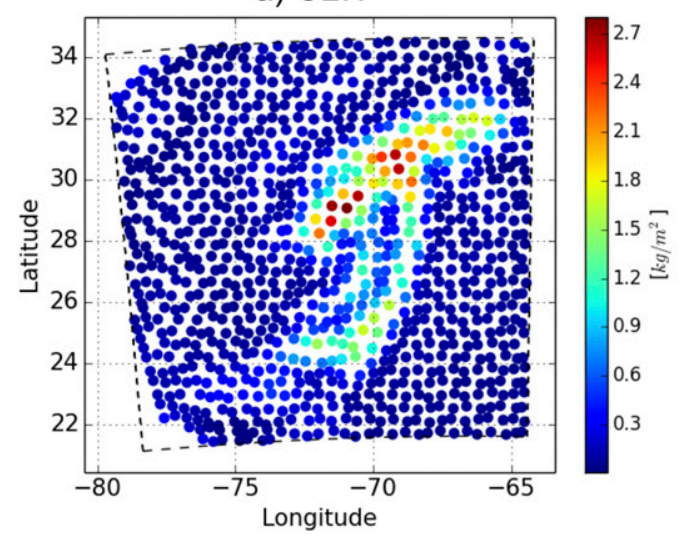

c) CLWavg

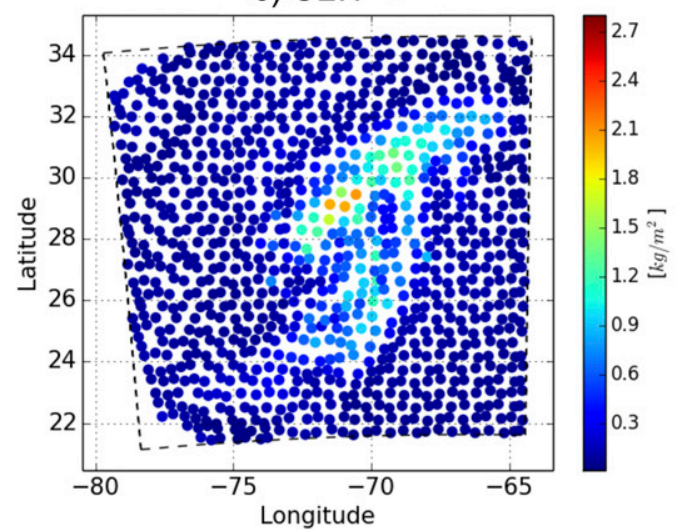

b) CLWfg

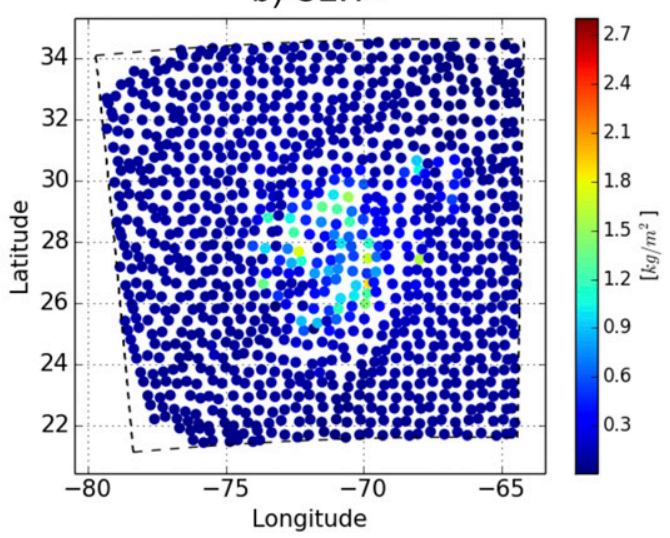

d) Symmetric Observation Error

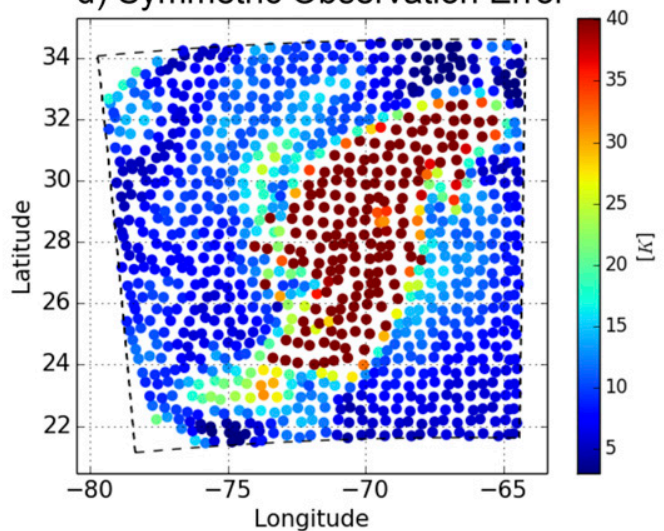

FIG. 2. Cloud amount $\left(\mathrm{kg} \mathrm{m}^{-2}\right)$ estimated from (a) observed and (b) first guess brightness temperatures at channel 2 of ATMS valid at 1800 UTC 26 Aug 2014. (c) Averaged cloud amount $\left(\mathrm{kg} \mathrm{m}^{-2}\right)$ of (a) and (b). (d) Symmetric observation error (K).

microphysical scheme, is contained in $\mathrm{Wu}$ and Zupanski (2017). As part of the partition procedure, the computation of particle size of each of the six habits is also provided and will now be discussed. The cloud water effective radius ( efr $_{-} q_{l}$ ) is a function of temperature and is expressed as

$$
\begin{aligned}
\text { efr_ } q_{l}= & 1.5(5+5 \\
& \times \min \{1, \max [0.0,0.05(273.15-T)]\}),
\end{aligned}
$$

where $T$ is temperature $(\mathrm{K})$. As a result, cloud water effective radius ranges from 7.5 to $15 \mu \mathrm{m}$. Unlike cloud water effective radius, the effective radius of both cloud ice (efr $\left.\_q_{i}\right)$ and rain (efr $\left.\_q_{r}\right)$ is set to a constant value of 75 and $450 \mu \mathrm{m}$, respectively. Finally, the effective radius of snow (efr_ $\left.q_{s}\right)$, graupel (efr_ $\left.q_{g}\right)$, and hail $\left(\right.$ efr_$\left.\_q_{h}\right)$ is computed using

$$
\text { efr } \_q_{x}=1.5\left(\frac{\rho_{\text {air }} \times q_{t i}}{\pi \times \rho_{x} \times N_{i}}\right)^{1 / 3} \times 10^{6},
$$

where the subscript $x$ can be substituted for $s$ (snow), $g$ (graupel), or $h$ (hail); $\rho_{\text {air }}$ is air density $\left(\mathrm{kg} \mathrm{m}^{-3}\right) ; q_{t i}$ is total frozen mass; $\pi$ is $\arccos (-1) ; N_{i}$ is the number concentration of ice and is set to a constant value of $2 \times 10^{4}\left(\right.$ No. $\left.\mathrm{m}^{-3}\right)$; and $\rho_{x}\left(\mathrm{~kg} \mathrm{~m}^{-3}\right)$ is the density of snow, graupel, or hail, which is a function of riming rate as described by

$$
\left\{\begin{array}{lll}
\rho_{x}=\rho_{s}=100 & \text { if } & \text { F_RIMEF } \leq 5 \\
\rho_{x}=\rho_{g}=400 & \text { if } & 5<\text { F_RIMEF } \leq 20 . \\
\rho_{x}=\rho_{h}=900 & \text { if } & \text { F_RIMEF }>20
\end{array}\right.
$$

\section{3) QuALiTy CONTROL}

Currently, operational HWRF only considers clearsky radiance assimilation for ocean-only scenes. There are many steps in the preparation for clear-sky assimilation; however, only those relevant to this study are discussed here. To begin, radiances over land are removed. Next, a cloud-clearing procedure is imposed in 


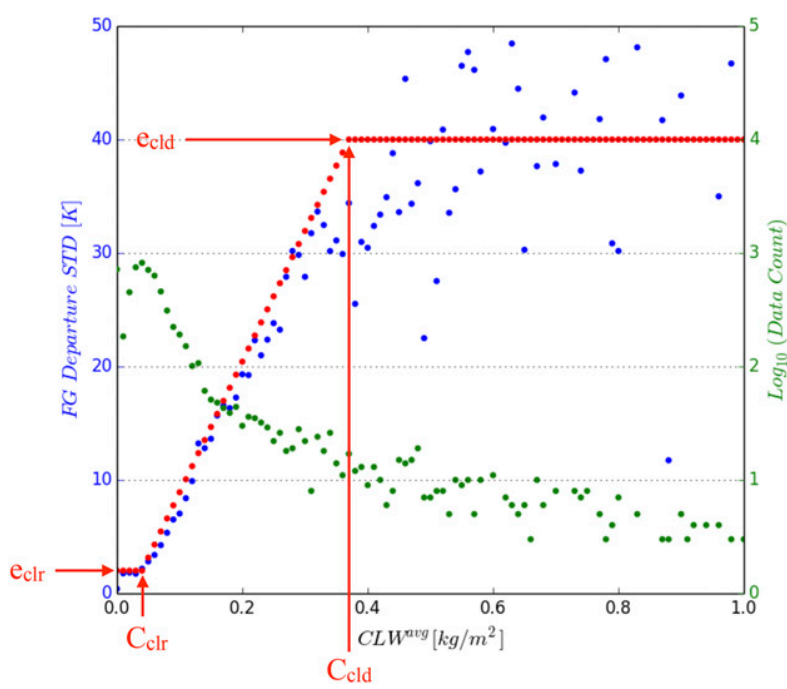

FIG. 3. Symmetric observation error model for ATMS channel 2: standard deviation of first guess ( $\mathrm{K}$; blue dots), assigned symmetric observation error (K, red dots), and $\log _{10}$ of numbers of ATMS data (green dots) from the nine HWRF first guesses (Table 2) from four 2014 Atlantic hurricanes. The bin width for CLW ${ }^{\text {avg }}$ is $0.01 \mathrm{~kg} \mathrm{~m}^{-2}$.

which cloudy and precipitation-affected satellite radiances are removed [additional details are provided by Zou et al. (2013)]. Last, large differences (3 times the prescribed observation errors) between observations and first guess are removed during the so-called gross check procedure. Of the three quality control steps previously listed, the cloud-clearing procedure is removed to facilitate for all-sky assimilation. There is a modification of the interpretation of the gross check procedure that requires mention: observation errors for clear-sky satellite radiances are spectrally constant. However, observation errors for all-sky satellite radiances are dependent on cloud amount, as described in section $2 \mathrm{~d}(1)$.

\section{4) BIAS CORRECTION}

Once quality control has been completed, radiances will be bias corrected. In the current operational HWRF data assimilation procedure, no radiance bias-correction coefficients are calculated or updated. Instead, biascorrection coefficients from GDAS are used, and these coefficients are not allowed to change during the cost function minimization within an HWRF data assimilation cycle. In global operational practice, the GDAS biascorrection coefficients are updated using the enhanced radiance bias-correction scheme (VarBC) developed by Zhu et al. $(2014,2016)$ during each data assimilation cycle. Following the operational HWRF configuration, ATMS radiance bias-correction coefficients from GDAS are used for the current study. This is necessary because of the short cycling period of HWRF (HWRF only runs when a
TABLE 2. The nine HWRF first guesses from four selected 2014 Atlantic hurricanes, which are used to compute the thresholds used by the symmetric observation error model.

\begin{tabular}{lll}
\hline \hline Cases & \multicolumn{1}{c}{ First guess valid date } & \multicolumn{1}{c}{ Status } \\
\hline Arthur & 1800 UTC 2 Jul 2014 & Tropical storm \\
& 1800 UTC 3 Jul 2014 & Hurricane \\
Cristobal & 1800 UTC 24 Aug 2014 & Tropical storm \\
& 1800 UTC 26 Aug 2014 & Hurricane \\
Edouard & 0600 UTC 14 Sep 2014 & Tropical storm \\
& 0600 UTC 16 Sep 2014 & Hurricane \\
& 0600 UTC 17 Sep 2014 & Hurricane \\
Gonzalo & 0600 UTC 13 Oct 2014 & Tropical storm \\
& 0600 UTC 17 Oct 2014 & Hurricane \\
\hline
\end{tabular}

tropical system of interest is present) and the relative small and moving nature of ghost-d02 and ghost-d03 of HWRF, both of which introduce additional challenges to calculate bias-correction coefficients for the application herein. There have been attempts to perform radiance bias correction for a limited-area domain. For example, Yang et al. (2016) employed a single WRF domain with a spatial coverage much larger than ghost-d03 of HWRF, which allows continuous collection of AMSR2 data and therefore a consistent estimation of radiance bias-correction coefficients.

\section{Experiments}

\section{a. Case study}

Hurricane Cristobal, which occurred during the 2014 Atlantic season, is used in this study. Cristobal is selected because its lifespan extended beyond 5 days, and it maintained hurricane status for several days. Another factor for choosing Cristobal is that more ATMS data were available for assimilation due to the longevity of the system. In Fig. 4, the National Hurricane Center (NHC) best track for Cristobal is displayed. As is seen in the figure, the genesis of Cristobal began on 23 August near $21.5^{\circ} \mathrm{N}$ and $72^{\circ} \mathrm{W}$. Cristobal then intensified into a tropical storm between 24 and 25 August, after which the system intensified into a hurricane on 26 August. Cristobal reached its peak intensity of $75 \mathrm{kt}\left(\sim 39 \mathrm{~m} \mathrm{~s}^{-1}\right)$ by 1800 UTC 28 August. While continuing to move northeastward, Cristobal weakened into an extratropical system during 29 August and remained extratropical at the end of its life on 1 September while passing over Iceland.

\section{b. Experimental design}

For the study described in this paper, two data assimilation experiments are conducted:

1) The clear-sky ocean-only experiment (AddATMS CLRSKY) uses the 2015 HWRF operational 


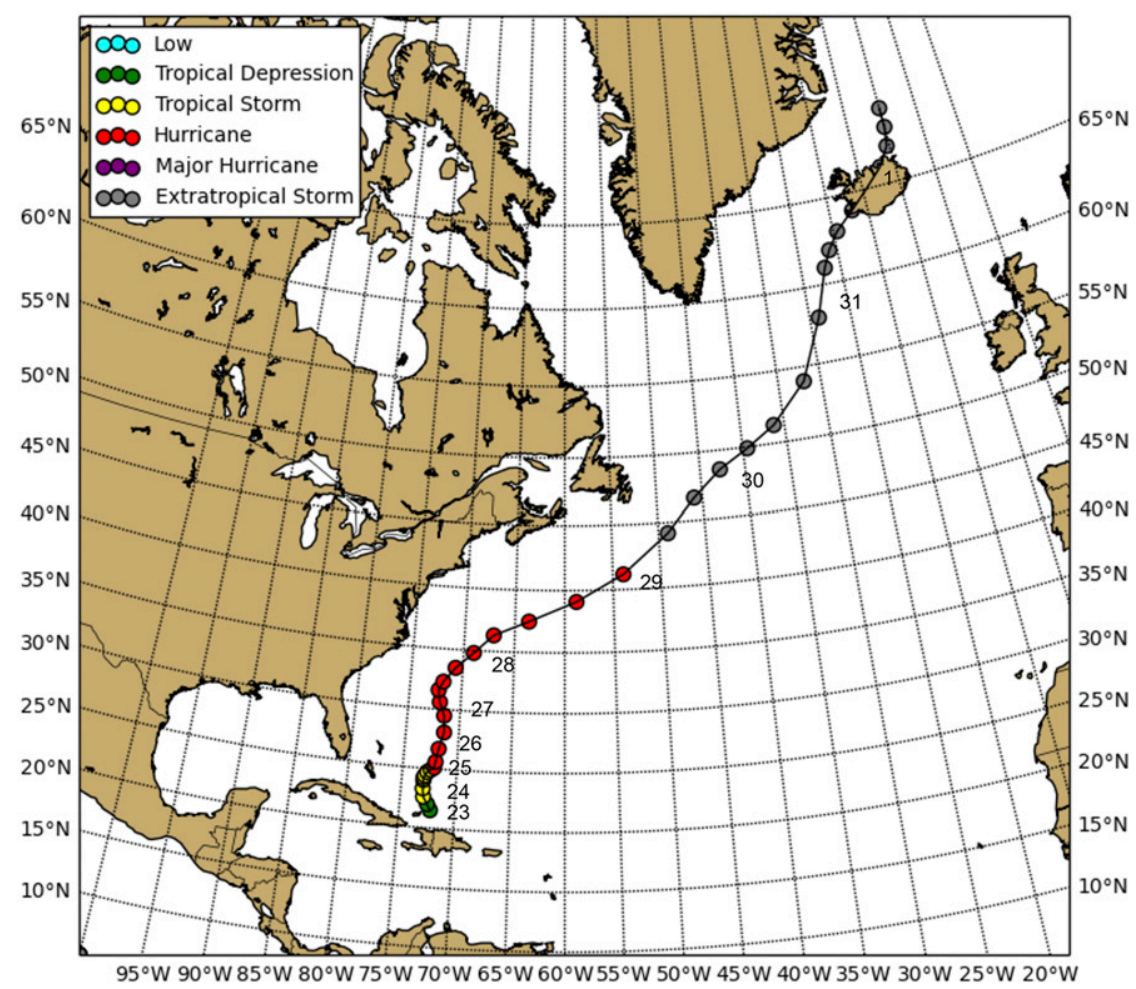

FIG. 4. NHC best track of Hurricane Cristobal (2014). Storm intensity is indicated by colors at 6-h interval from 23 Aug to 1 Sep 2014.

configuration (see section 2a) and assimilates the default observations. ${ }^{1}$ In addition, clear-sky ATMS radiances from channels $1-4,7-9$, and 16 (Table 1 ) are assimilated in ghost-d03.

2) The all-sky ocean-only experiment (AddATMS ALLSKY) modifies the operational configuration by following the procedures described in sections $2 \mathrm{~b}-\mathrm{d}$ and assimilates the default observations and ATMS all-sky radiances from channels $1-4,7-9$, and 16 in ghost-d03.

The AddATMS_CLRSKY experiment is configured to mimic the HWRF operational run, in which there is no preparation of cloud microphysical variables in the background; only clear-sky ATMS radiances are used. The CWM is not included as a control variable, and the six hydrometeor habits are not used as state variables. In contrast, the AddATMS_ALLSKY experiment follows the procedures described in sections $2 \mathrm{~b}-\mathrm{d}$, which

\footnotetext{
${ }^{1}$ Operational default: In ghost-d02, conventional observations contained in prepbufr file, satellite-derived winds, GPS RO data, and satellite clear-sky radiances from HIRS, AIRS, IASI, CrIS, GOES Sounders, AMSU-A, MHS, and ATMS are assimilated. In ghost-d03, only conventional observations contained in prepbufr file are assimilated.
}

facilitates the all-sky radiance assimilation capability and enables the cycling and update of cloud microphysical variables.

For both experiments, 10 consecutive data assimilation cycles are conducted from 1200 UTC 24 August to 1800 UTC 26 August 2014, and analyses are generated every $6 \mathrm{~h}$. Because of the orbital period of $S N P P$, ATMS radiances are available within ghost-d03 near 0600 and 1800 UTC for Cristobal. Subsequently, only five cycles contain ATMS radiance data for assimilation. For those cycles that occur at 0000 and 1200 UTC, only conventional observations are assimilated into ghost-d03 for both experiments. Finally, a box of $45 \mathrm{~km} \times 45 \mathrm{~km}$ is used to thin the ATMS data for both experiments.

\section{c. Initial conditions for the HWRF forecast}

As mentioned in section 2a, the blending procedure is activated during the operational HWRF runs to remove analysis increments within $150-\mathrm{km}$ radius from the hurricane center and below $400 \mathrm{hPa}$ and blend analysis and background from a $150-$ to a $300-\mathrm{km}$ radius. To preserve analysis increments associated with the assimilation of ATMS all-sky radiances in the hurricane center, the blending procedure is disabled for both the AddATMS_CLRSKY experiment 
a) $\mathrm{Ch} 1(23.8 \mathrm{GHz})$
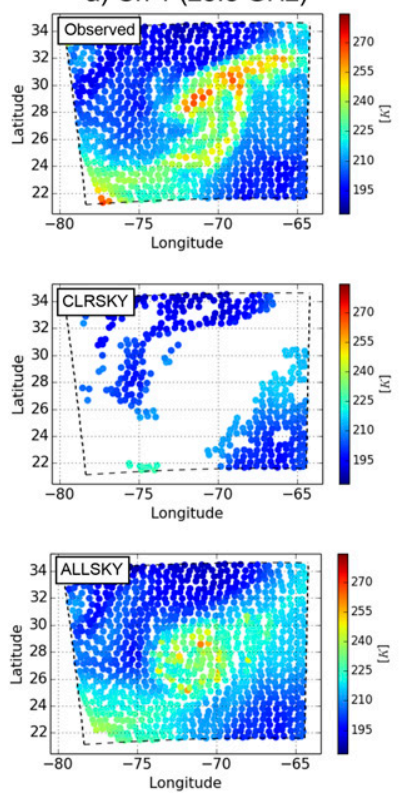

b) $\mathrm{Ch} 2(31.4 \mathrm{GHz})$
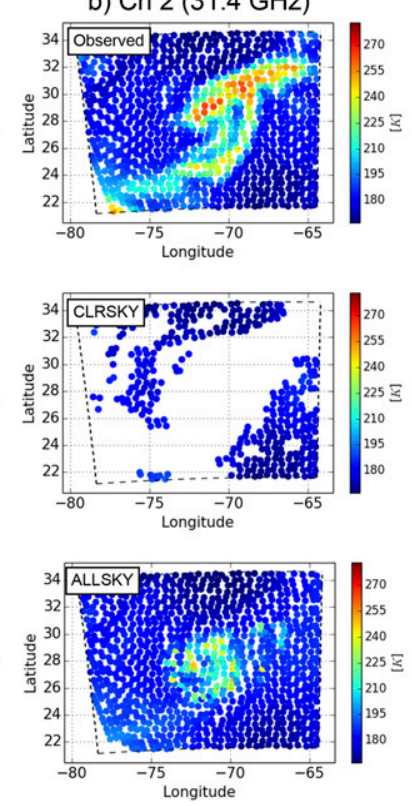

c) $\operatorname{Ch} 3(50.3 \mathrm{GHz})$
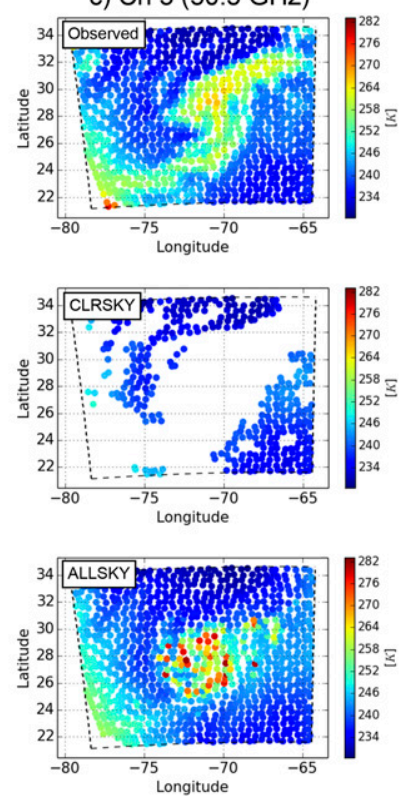

d) $\mathrm{Ch} 4(51.76 \mathrm{GHz})$
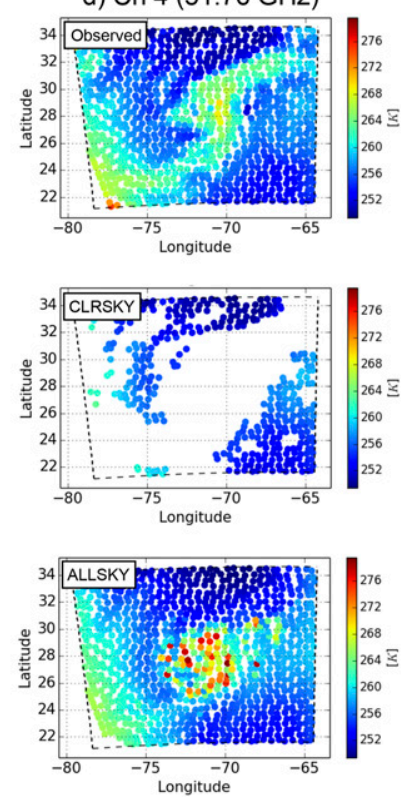

FIG. 5. ATMS brightness temperatures (K) of (a) $23.8 \mathrm{GHz}$ (channel 1), (b) $31.4 \mathrm{GHz}$ (channel 2), (c) $50.3 \mathrm{GHz}$ (channel 3 ), and (d) $51.76 \mathrm{GHz}$ (channel 4) valid at 1800 UTC 26 Aug 2014 during Cristobal. (top) Observation, and the first guess/background from the (middle) AddATMS_CLRSKY and (bottom) AddATMS_ALLSKY experiment.

and the AddATMS_ALLSKY experiment for the current study.

\section{Results from data assimilation}

\section{a. Observed and first guess ATMS radiances}

Observed and first guess ATMS radiance fields of the eight selected channels for the two experiments at the last cycle are examined. Observed ATMS data, channels 1-4 (Table 1), valid approximately at 1800 UTC 26 August 2014, are displayed along the top row of Fig. 5. Because of small values of spectrally dependent emissivity of ocean water, brightness temperatures are exceedingly small $(\sim 180 \mathrm{~K})$ for channels 1 and 2 , while values increase to approximately $250 \mathrm{~K}$ for channels 3 and 4 over clear-sky ocean scenes. As a result, brightness temperatures of cloudy and precipitationaffected pixels are, by comparison, significantly larger. Such large brightness temperature differences between ocean-only and cloudy pixels provide a distinct advantage for the use of microwave imagery, compared to infrared imagery of tropical systems over the open ocean. A second piece of information is now required: imagery of the first guess.

To compute brightness temperatures for the first guess field of AddATMS_CLRSKY, the CRTM is employed without hydrometeor information. During quality control, a cloud-clearing procedure is activated to identify the location of observed cloudy and precipitationaffected pixels and then to remove CRTM radiance data from the first guess at the same locations. A last step of the quality control procedure is the removal of data from the CRTM radiance field where values of the innovation exceed a threshold [see section $2 \mathrm{~d}(3)$ ]. As a consequence of the cloud-clearing procedure, features associated with simulated Cristobal are removed and therefore absent, as indicated by blank regions of the panels displayed in the second row of Fig. 5. In contrast, all hydrometeor information is used by the CRTM to compute brightness temperatures for the first guess field of the AddATMS_ALLSKY case. Similar to the AddATMS_CLRSKY case, innovation excesses are removed during the gross check procedure, although the thresholds are different, as the all-sky observation error assignment is used [see section $2 \mathrm{~d}(1)$ ]. The resulting brightness temperatures are displayed in the bottom row of Fig. 5. Channels 7-9 and 16 (Table 1) are processed in a similar fashion, and results are shown in Fig. 6 for completeness. All data shown in Figs. 5 and 6 are then used in data assimilation.

Some interpretations of the brightness temperatures for the AddATMS_ALLSKY experiment are aided by the use of Fig. 7. In Fig. 7, two vertically integrated quantities are shown: water vapor, also referred to as total precipitable water (TPW; Fig. 7a), and liquid condensate that includes the sum of $q_{l}$ and $q_{r}$ (Fig. 7b). 
a) $\mathrm{Ch} 7(54.4 \mathrm{GHz})$
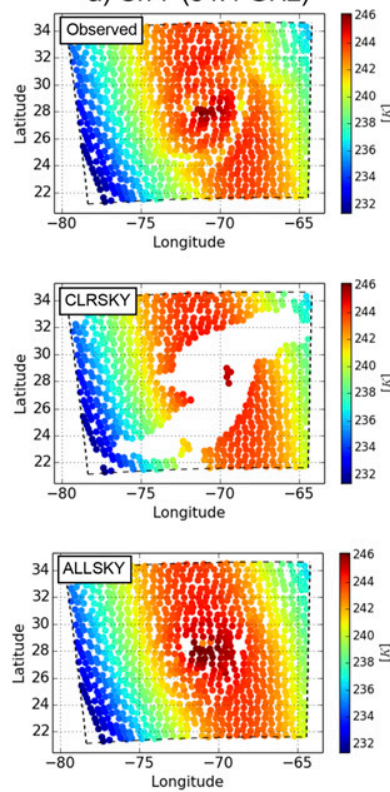

b) $\mathrm{Ch} 8(54.9 \mathrm{GHz})$
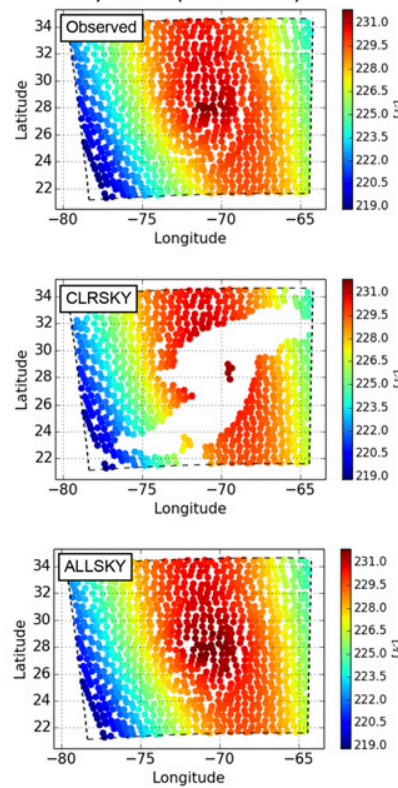

c) Ch 9 (55.5 GHz)
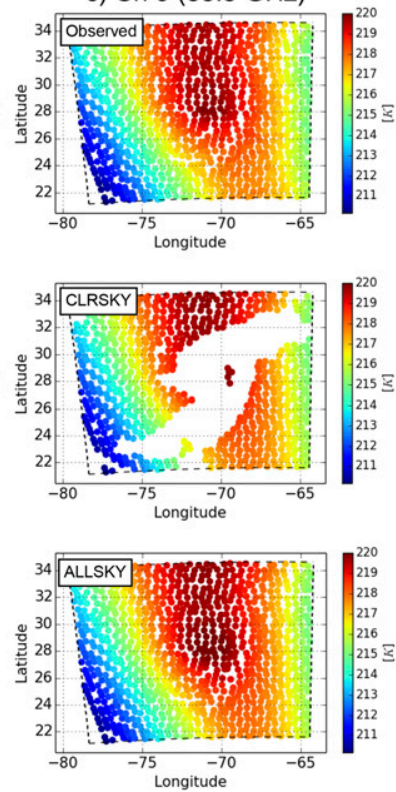

d) $\mathrm{Ch} 16(87.9 \mathrm{GHz})$
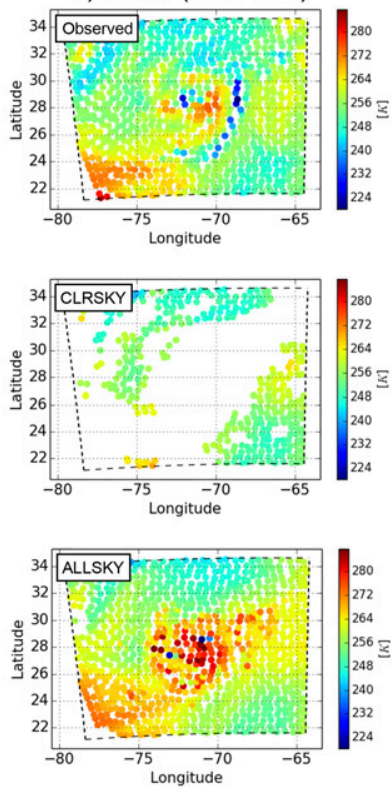

FIG. 6. As in Fig. 5, but for (a) $54.4 \mathrm{GHz}$ (channel 7), (b) $54.9 \mathrm{GHz}$ (channel 8), (c) $55.5 \mathrm{GHz}$ (channel 9), and (d) $87.9 \mathrm{GHz}$ (channel 16).

Both panels in Fig. 7 are generated using the first guess from the AddATMS_ALLSKY experiment valid at 1800 UTC 26 August. To begin, the pattern of values of TPW greater than $\sim 60 \mathrm{~mm}$ (black contour in Fig. $7 \mathrm{a}$ ) corresponds with the moderately warm regions (250$264 \mathrm{~K}$ in Fig. $5 \mathrm{c}$ and $260-268 \mathrm{~K}$ in Fig. $5 d$ ) in the vicinity of Cristobal. In addition, circular pixels that had brightness temperatures greater than $270 \mathrm{~K}$ from Figs. $5 \mathrm{c}$ and $5 \mathrm{~d}$ are displayed as open black circles in Fig. 7b. As can be seen, regions of integrated liquid condensate were collocated with the open circles. In short, a direct comparison between Figs. 5c and 5d and Fig. 7 suggests that the warm brightness temperatures are a result of relative large values of TPW interior to Cristobal and low-level liquid water condensate.

\section{b. Evaluation of the all-sky assimilation procedure}

Since HWRF is run for clear-sky scenarios in operations, only results from AddATMS_ALLSKY will be discussed in this subsection. To evaluate the AddATMS_ALLSKY experiment, statistics for observation minus background $(O-B)$ and observation minus analysis $(O-A)$ for the a) Total Precipitable Water

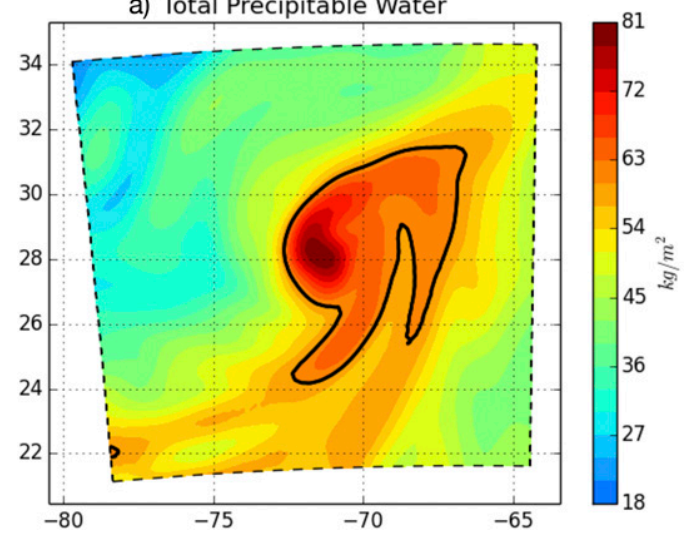

b) Integrated Liquid Condensate

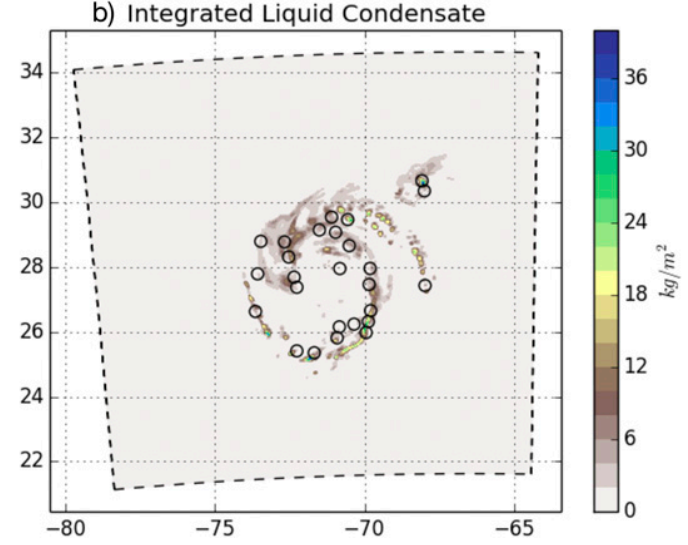

FIG. 7. (a) Total precipitable water $\left(\mathrm{kg} \mathrm{m}^{-2}\right)$ and (b) vertically integrated liquid condensate $\left(\mathrm{kg} \mathrm{m}^{-2}\right)$ from the first guess of the AddATMS_ALLSKY experiment valid at 1800 UTC 26 Aug (cycle 10). The unit $\mathrm{kg} \mathrm{m}^{-2}$ is equivalent to $\mathrm{mm}$ after dividing by density of liquid water, which is $1000 \mathrm{~kg} \mathrm{~m}^{-3}$. Liquid condensate in (b) includes cloud water $\left(q_{l}\right)$ and rain $\left(q_{r}\right)$. A thick black contour in (a) is used to indicate values of 60 . The open black circles in (b) denote brightness temperatures in Figs. 5c and 5d (channels 3 and 4) that are larger than $270 \mathrm{~K}$. 
TABLE 3. The four groups that are used to categorize all-sky radiances data into cloudy and clear-sky scenes based on the values of $\mathrm{CLW}^{\mathrm{obs}}$ and $\mathrm{CLW}^{\mathrm{fg}}$ and their thresholds; O: obs, F: first guess.

\begin{tabular}{lll}
\hline \hline \multicolumn{1}{c}{ Group } & \multicolumn{1}{c}{ Mathematical expression } & \multicolumn{1}{c}{ Description } \\
\hline O:cld/F:cld (black) & $\mathrm{CLW}^{\mathrm{obs}}>C_{\text {cld }}$ and $\mathrm{CLW}^{\mathrm{fg}}>C_{\text {cld }}$ & Both observation and first guess are cloudy \\
O:clr/F:clr (red) & $\mathrm{CLW}^{\mathrm{obs}} \leq C_{\text {clr }}$ and $\mathrm{CLW}^{\mathrm{fg}} \leq C_{\text {clr }}$ & Both observation and first guess are clear \\
O:clr/F:cld (green) & $\mathrm{CLW}^{\mathrm{obs}} \leq C_{\text {clr }}$ and $\mathrm{CLW}^{\mathrm{fg}}>C_{\text {cld }}$ & Observation is clear, and first guess is cloudy \\
O:cld/F:clr (blue) & $\mathrm{CLW}^{\mathrm{obs}}>C_{\text {cld }}$ and $C \mathrm{CW}^{\mathrm{fg}} \leq C_{\mathrm{clr}}$ & Observation is cloudy, and first guess is clear \\
\hline
\end{tabular}

five cycles that contain ATMS data are used. Values of $O-B$ and $O-A$ are normalized by symmetric observation errors for the AddATMS_ALLSKY experiment. Following Zhu et al. (2016), brightness temperatures are categorized into four groups based on the values of $\mathrm{CLW}^{\mathrm{fg}}$ and $C L W^{\text {obs }}$. Specifically, the four groups are 1) O:cld/F:cld, where both observation and first guess are considered cloudy; 2) O:clr/F:clr, where both observation and first guess are considered clear; 3) O:clr/ F:cld, where observation is clear while first guess is cloudy; and 4) O:cld/F:clr, where observation is cloudy while first guess is clear (see Table 3).

To begin with, statistics for channels $1-4$ are shown as histograms in Fig. 8. All four $O-B$ plots of group 1 (Fig. 8; left side, black contours) have the widest distribution and the highest peak, compared to the other three groups. These results suggest that most of the data in the observed and first guess satellite images are composed of cloudy and precipitation-affected pixels. On the right side of Fig. 8, the width of group 1 distributions for the $O-A$ plots decreased from that for the $O-B$ plots, and the peak of group 1 for $O-A$ greatly exceeds not only that of the other three groups, but also that of the corresponding group 1 plots for $O-B$. Overall, the above results suggest that a better fit to observation is achieved in the analysis for cloudy pixels. Similar to group 1, the group 2 distributions (Fig. 8; red contours) exhibit a bias (both positive and negative) for all four channels in the $O-B$ plots, and values of the biases have been reduced and shifted toward zero in the $O-A$ plots. Unlike groups 1 and 2, the key feature to focus on for group 3 (Fig. 8; green contours) and group 4 (Fig. 8; blue contours) is the reduction of the number of data points from $O-B$ to $O-A$, while it is expected that a small bias remains. A somewhat straightforward explanation can be provided for the negative bias in group 3 for the $O-B$ plots. Since the first guess has placed clouds (hence relatively warm microwave brightness temperatures) where observations were clear (hence relatively cold microwave brightness temperatures), values of $O-B$ are negative. As a result of data assimilation, the number of data points in group 3 has decreased from $O-B$ (715; channels 1-4) to $O-A$ (672; all eight channels) plots. A similar yet opposite explanation is offered for group 4. In this case, clouds were observed where the first guess had clear-sky scenes. As a result, values of $O-B$ are positive. Like group 3, the number of data points in group 4 has also decreased from $O-B$ (1294; channels 1-4) to $O-A$ (715; channels 1-4) plots.

Similarly, statistics for channels $7-9$ and 16 are shown as histograms in Fig. 9. Unlike channels 1-4, where the weighting functions peak in the lower troposphere, weighting functions for channels 7-9 peak in the upper troposphere/lower stratosphere. In particular, the weighting function for channel 7 peaks near the top of the cloud field of Cristobal. This explains why the number of pixels in group 2 (Fig. 9a; red contour) is similar to the number of pixels in group 1 (Fig. 9a; black contour). Notice that the number of pixels for group 2 dominates the distribution for channels 8-9 (Figs. 9b,c; red contour), which is a consequence of the weighting function for both channels peaking at levels above the cloud field of Cristobal. Similar to the behavior of the distributions from $O-B$ to $O-A$ for channels 1-4, the distributions in channels 7-9 narrow and shift toward zero. Although plots of each channel are arranged numerically, the behavior of the plot for channel 16 (Fig. 9d) is similar to those for channels 1-4. As indicated in Figs. 8 and 9, the shifting and narrowing of the distribution from $O-B$ to $O-A$ is evidence that the adjustment by data assimilation improved the fit to observation in some sense.

Despite the overall improved fit to observations in the $O-A$ plots, some noticeable biases (as indicated by the values of $\mu$ in Figs. 8 and 9) still exist in both $O-B$ and $O-A$ plots. One possible reason may be the uncertainties of optical properties associated with the CRTM that are used to compute brightness temperatures. In addition, the values of emissivity for the ocean between observation and those contained in the CRTM, the vertical distribution and absolute values of water vapor, and the values of observed SST versus those contained in the HWRF first guess may also play a role. Furthermore, the use of global bias-correction coefficients, along with no update of the coefficients during the minimization of cost function within each HWRF data assimilation cycle, as discussed in section $2 \mathrm{~d}(4)$, may also 
a)

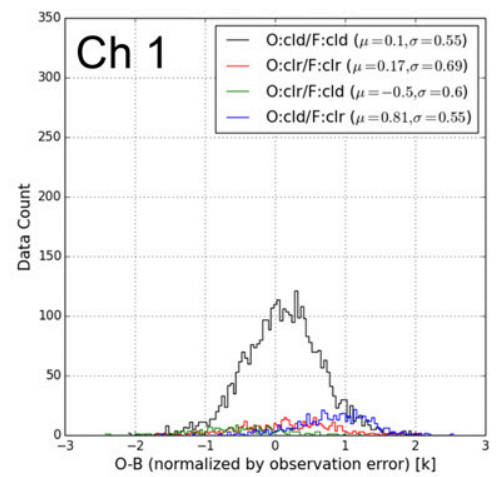

b)

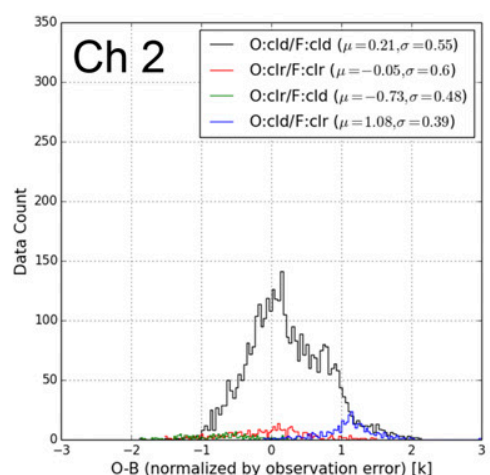

c)

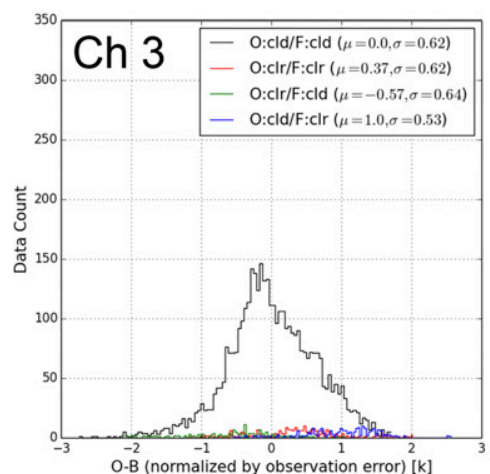

d)

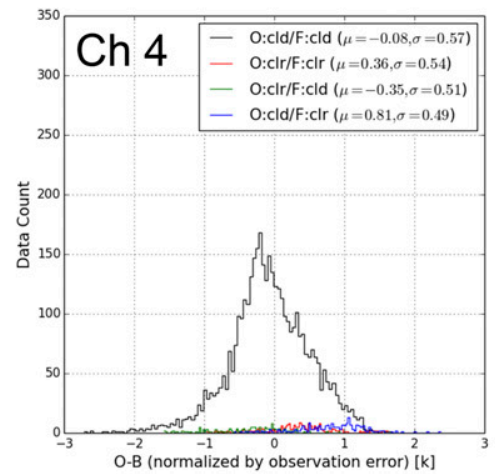

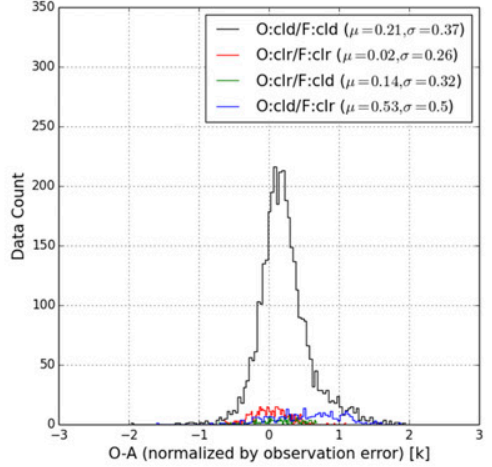
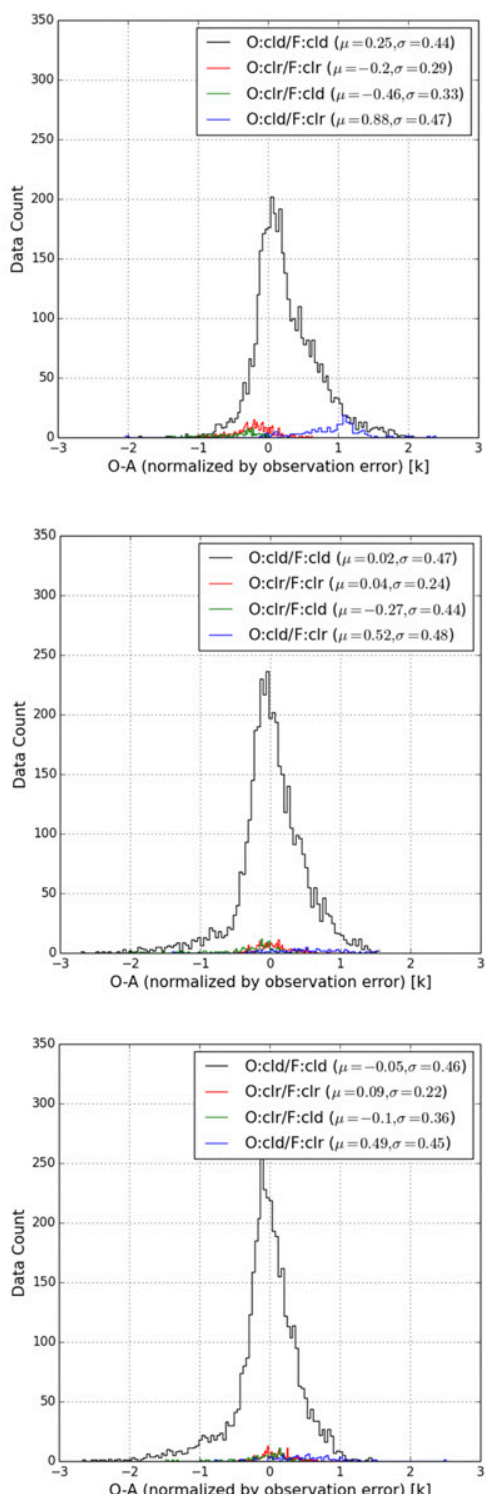

FIG. 8. Histogram of normalized (left) $O-B$ and (right) $O-A$ from the five cycles of AddATMS_ALLSKY experiments when ATMS was available within the ghost-d03 of HWRF (normalized by symmetric observation error): (a) $23.8 \mathrm{GHz}$ (channel 1), (b) $31.4 \mathrm{GHz}$ (channel 2), (c) $50.3 \mathrm{GHz}$ (channel 3), and (d) $51.76 \mathrm{GHz}$ (channel 4). Parameter $\mu$ denotes mean, and $\sigma$ is standard deviation. 
a)

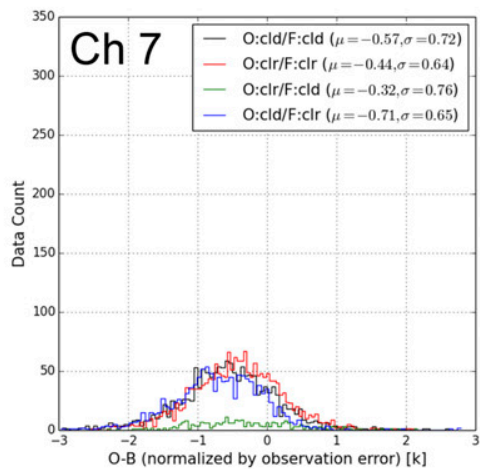

b)

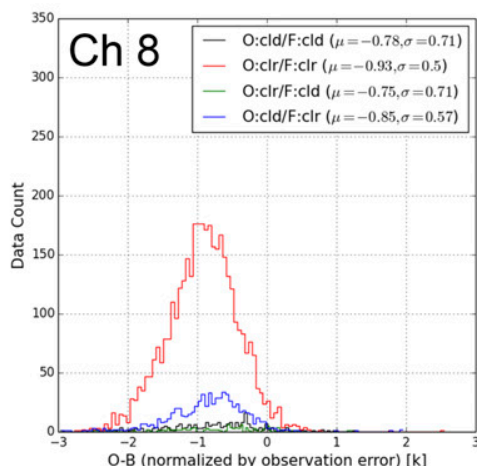

c)
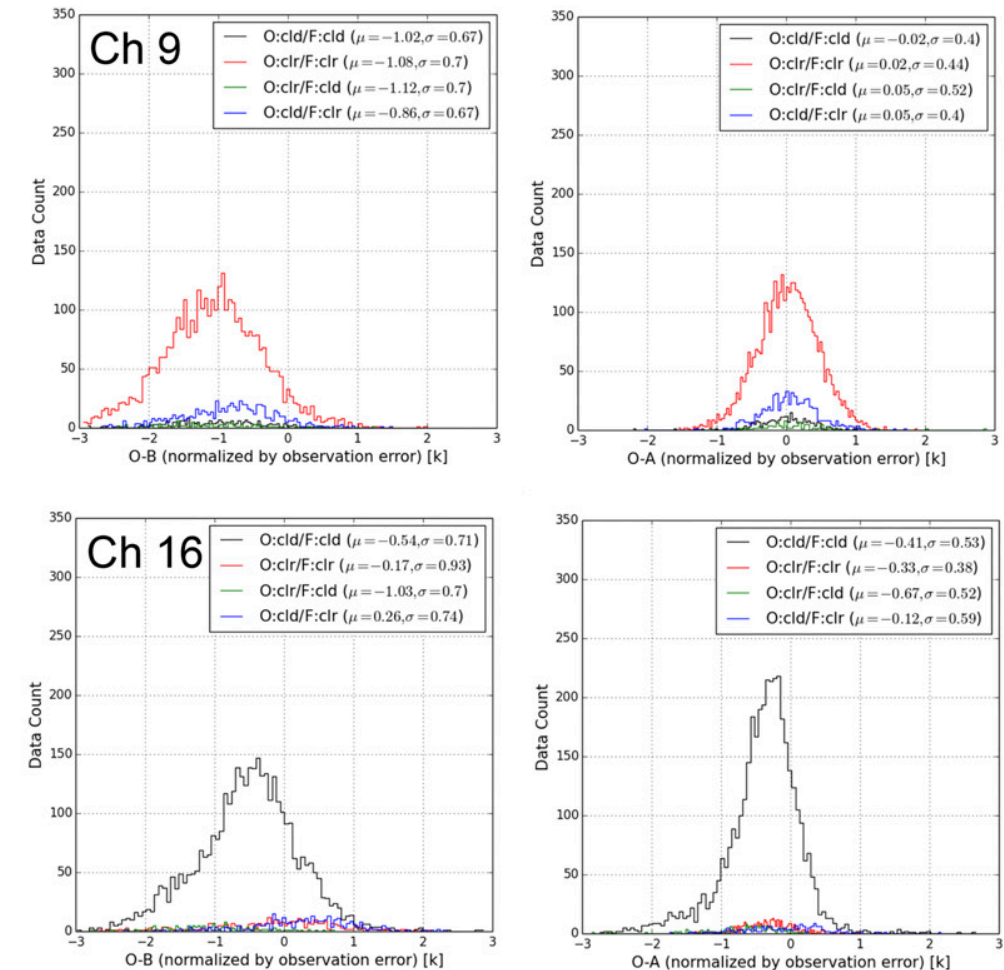
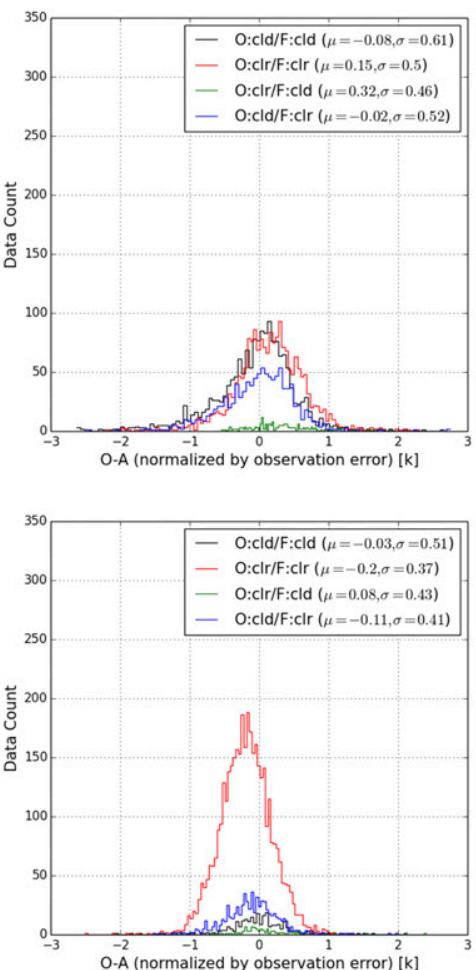

O-A (normalized by observation error) $[\mathrm{k}]$

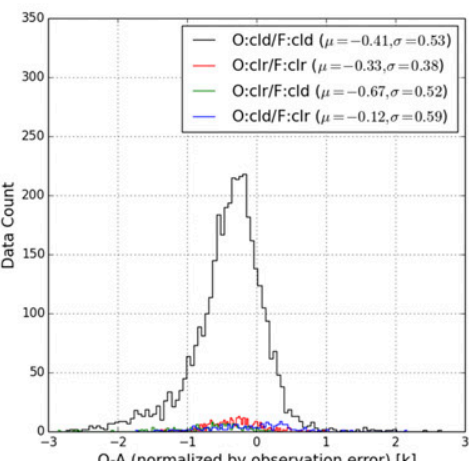

O-A (normalized by observation error) [k]

FIG. 9. As in Fig. 8, but for (a) $54.5 \mathrm{GHz}$ (channel 7), (b) $54.9 \mathrm{GHz}$ (channel 8),

(c) $55.5 \mathrm{GHz}$ (channel 9), and (d) $87.9 \mathrm{GHz}$ (channel 16). 
TABLE 4. The mean and standard deviation of normalized $O-B$ without and with bias corrections for the four groups listed in Table 3 . Values of mean $\mu$ and standard deviation $\sigma$ in bold are used to show reductions after applying bias corrections.

\begin{tabular}{|c|c|c|c|c|c|c|c|c|}
\hline & \multicolumn{8}{|c|}{ Mean $\mu$ and standard deviation $\sigma$ in kelvin: $\mu(\sigma)$} \\
\hline & \multicolumn{4}{|c|}{ Without bias correction } & \multicolumn{4}{|c|}{ With bias correction } \\
\hline & O:cld/F:cld & $\mathrm{O}: \mathrm{clr} / \mathrm{F}: \mathrm{clr}$ & O:clr/F:cld & O:cld/F:clr & O:cld/F:cld & O:clr/F:clr & O:clr/F:cld & O:cld/F:clr \\
\hline 1 & $0.24(0.53)$ & $0.45(0.7)$ & $-0.25(0.64)$ & $1.0(0.54)$ & $0.1(0.55)$ & $0.17(0.69)$ & $-0.5 \mathbf{( 0 . 6 )}$ & $\mathbf{0 . 8 1}(0.55)$ \\
\hline 2 & $0.31(0.54)$ & $0.2(0.61)$ & $-0.44(0.54)$ & $1.14(1.07)$ & $\mathbf{0 . 2 1}(0.55)$ & $-0.05(0.6)$ & $-0.73(\mathbf{0 . 4 8 )}$ & $1.08(0.39)$ \\
\hline 3 & $0.18(0.64)$ & $0.88(0.65)$ & $-0.11(0.7)$ & $1.26(0.63)$ & $0.0(0.62)$ & $0.37(0.62)$ & $-0.57(\mathbf{0 . 6 4 )}$ & $1.0(0.53)$ \\
\hline 4 & $-0.11(0.6)$ & $0.43(0.54)$ & $-0.34(0.51)$ & $0.84(0.53)$ & $-0.08(0.57)$ & $0.36(0.54)$ & $-0.35(\mathbf{0 . 5 1})$ & $0.81(0.49)$ \\
\hline 7 & $-0.64(0.72)$ & $-0.66(0.9)$ & $-0.64(0.89)$ & $-0.93(0.78)$ & $-0.57(0.72)$ & $-0.44(0.64)$ & $-0.32(0.76)$ & $-0.71(0.65)$ \\
\hline 8 & $-1.57(0.7)$ & $-2.46(0.64)$ & $-2.0(0.81)$ & $-2.06(0.84)$ & -0.78 $(0.71)$ & $-0.93(0.5)$ & $-0.75(0.71)$ & $-0.85(0.57)$ \\
\hline 9 & $-2.86(0.79)$ & $-4.04(0.82)$ & $-3.67(0.88)$ & $-3.33(1.1)$ & $-1.02(0.67)$ & -1.08 (0.7) & $-1.12(0.7)$ & $-0.86(0.67)$ \\
\hline 16 & $-0.4(0.72)$ & $0.24(0.94)$ & $-0.66(0.79)$ & $0.5(0.77)$ & $-0.54(\mathbf{0 . 7 1})$ & $-0.17(0.93)$ & $-1.03(\mathbf{0 . 7 )}$ & $0.26(0.74)$ \\
\hline
\end{tabular}

contribute to the resulting biases. Nevertheless, using global bias-correction coefficients still shows improvements, compared to not using any bias corrections. Table 4 summarizes the mean and standard deviation of the normalized $O-B$ without and with bias corrections for all four groups. In general, the biases (positive or negative mean) and the standard deviations are smaller (bold) when bias corrections are used with the global coefficients. There are only a few exceptions (channel 16 for groups 1 and 3 and channels 1-4 for group 3).

\section{c. Comparison of observed and CRTM imagery: Microwave}

Observed imagery from the Global Precipitation Measurement Mission (GPM) Microwave Imager (GMI) serves as an independent observation that is used to further evaluate an analysis field through the use of synthetic satellite images generated from HWRF outputs. Synthetic imagery has been used in previous studies to help improve NWP and interpretation of forecasts (Bikos et al. 2012; Grasso et al. 2014). For the study herein, the CRTM is used to generate synthetic GMI imagery. One purpose for comparing an analysis field to an independent observation is to evaluate the realism of an analysis field, which is similar to comparing results of a simulation of meteorological fields directly with observations. In this study, the choice was made to use satellite imagery since satellite radiances could be interpreted as a $2 \mathrm{D}$ projection of $3 \mathrm{D}$ atmospheric fields.

Synthetic GMI imagery at $89 \mathrm{GHz}$ of the analysis fields is compared directly to observed imagery. Unlike sensors on board geostationary satellites, an overpass from a microwave sensor such as GMI on board GPM can easily miss the feature of interests due to its unique orbit that leads to infrequent revisit time over the same target. Out of the 10 data assimilation cycles, only three GMI overpasses coincide with Cristobal during the time period of this study. These passes are valid near
1800 UTC 24 August (cycle 2), 0600 UTC 26 August (cycle 8), and 1800 UTC 26 August (cycle 10). A side-byside comparison of observed imagery and synthetic imagery for the AddATMS_ALLSKY case is displayed in Fig. 10. As seen in Figs. 10a-c, observed GMI imagery of Cristobal during different phases of its life cycle is shown. Unluckily, only a small portion of Cristobal was captured by the GMI overpass near 1800 UTC 24 August (Fig. 10a) and near 0600 UTC 26 August (Fig. 10b). However, most of the storm was captured at 1800 UTC 26 August (Fig. 10c), which exhibits the typical spiral pattern of a tropical storm. Although there is no such thing as data void in a synthetic satellite image (cf. Figs. 10a,b with $10 \mathrm{~d}, \mathrm{e})$, a direct comparison of synthetic data with observed is challenging due to missing data in Figs. 10a and 10b. In Fig. 10c, a relatively small portion of the lower-right corner is missing; however, the dominant spiral pattern of the observed storm supports the structure in the synthetic imagery (Fig. 10f). Because of the lack of clouds, a direct comparison between the AddATMS_CLRSKY case and the AddATMS_ALLSKY case is unnecessary.

\section{d. Comparison of observed and CRTM imagery: Infrared}

In addition to the observed GMI imagery, observed infrared imagery from the GOES is used as another set of independent observations to further evaluate the analysis. Synthetic $10.7-\mu \mathrm{m}$ GOES-13 imagery of the analysis fields is compared directly to observed imagery. Because $10.7 \mu \mathrm{m}$ is within the so-called atmospheric window, radiation emitted from the surface of Earth and cloud tops, which exist at different levels of the troposphere, provides a quasi-3D structure of Cristobal. Similar to Fig. 10, a side-by-side comparison of observed GOES-13 imagery at $10.7 \mu \mathrm{m}$ and the corresponding synthetic satellite images for the AddATMS_ALLSKY case are displayed in Fig. 11. A comparison of observed and synthetic imagery for the first two cycles of the 
a)

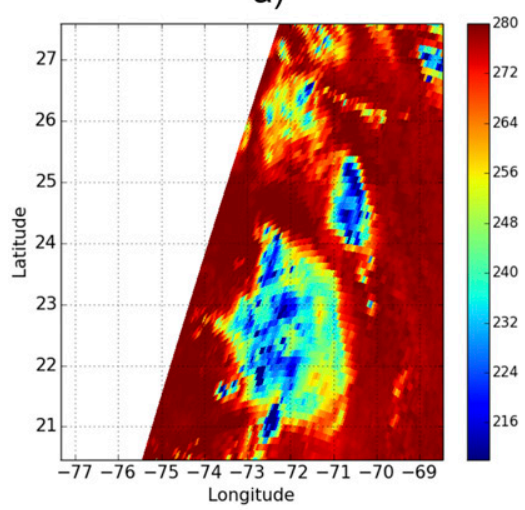

d)

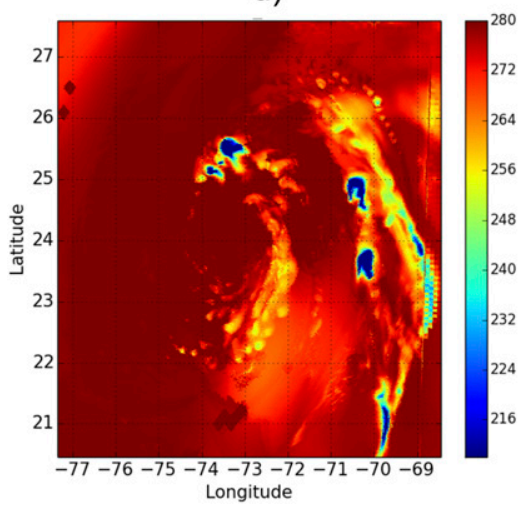

b)

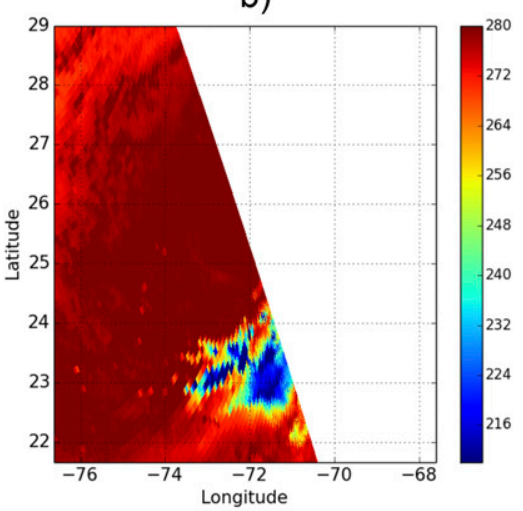

e)

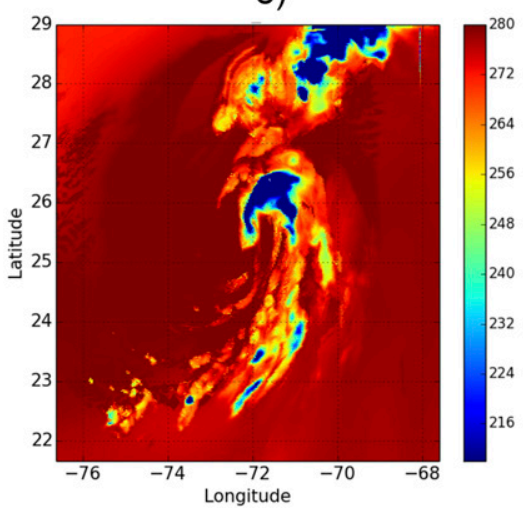

c)

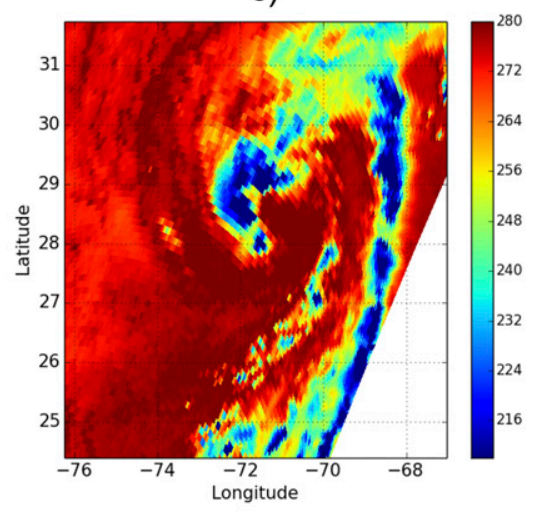

f)

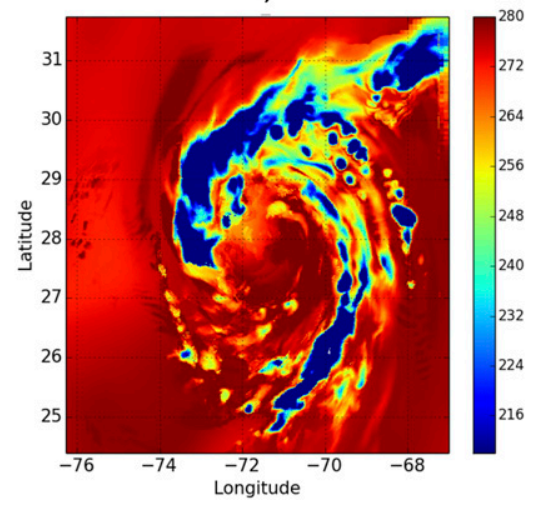

FIG. 10. GMI 89-GHz microwave imagery (brightness temperature in K) valid near (a) 1800 UTC 24 Aug (cycle 2), (b) 0600 UTC 26 Aug (cycle 8), and (c) 1800 UTC 26 Aug (cycle 10). (d)-(f) As in (a)-(c), but for synthetic satellite images from the corresponding AddATMS_ ALLSKY analyses. There were no GMI overpasses over Cristobal near the analysis times 0600 (cycle 4) and 1800 UTC 25 Aug (cycle 6).

AddATMS_ALLSKY case (Figs. 11a,b and 11f,g) indicates a lack of cold clouds in the analyses. However, subsequent analyses (Figs. 11c-e and $11 \mathrm{~h}-\mathrm{j}$ ) have cold cloud signatures that are comparable to observations. Another way to compare synthetic imagery of the analyses with observations is through the use of histograms. To make a given histogram, data from all five images in a given row of Fig. 11 are used to produce a curve as shown in Fig. 12a. For example, images in the first (second) row of Fig. 11 are used to produce the black (green) curve in Fig. 12a. Because of the lack of clouds, the histogram for the AddATMS_CLRSKY case (blue circles) is zero for temperatures less than approximately $290 \mathrm{~K}$. As was discussed above, the lack of cold clouds during the first two cycles (Figs. 11f,g) explains the discrepancy between the histogram of the AddATMS_ALLSKY case (green triangles) and observations (Fig. 12a) for temperatures less than $220 \mathrm{~K}$. For temperatures greater than $220 \mathrm{~K}$, the histogram of the AddATMS_ALLSKY case is supported by observations.

One main motivation for the assimilation of all-sky radiances is to generate an optimal initial state with realistic storm structure. Observed tropical storms have clouds; however, the initial state of the simulation of Cristobal in the AddATMS_CLRSKY case (which follows the operational configuration) has no clouds. In contrast, the initial state of the simulation of Cristobal in the AddATMS_ALLSKY case has clouds with a distribution that is supported by observations, as was shown in the histogram (Fig. 12). An additional consequence of having clouds in the initial state is a corresponding adjustment to thermodynamic variables that is consistent with the clouds. For example, a warm and moist anomaly is collocated with cloud condensate (not shown). Huang (1996) spoke of the importance of the consistency between cloud and other variables during data assimilation.

\section{HWRF forecast}

Differences between the AddATMS_CLRSKY and AddATMS_ALLSKY forecasts during the first few hours are worth exploring. Because there are no clouds in the analysis of the AddATMS_CLRSKY case, the 
a)

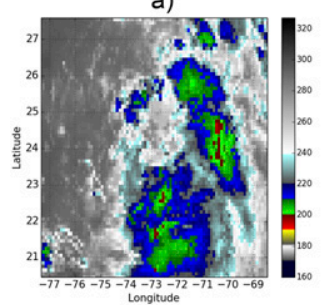

f)

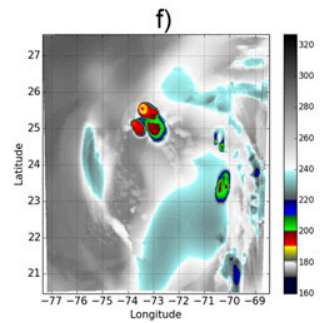

b)

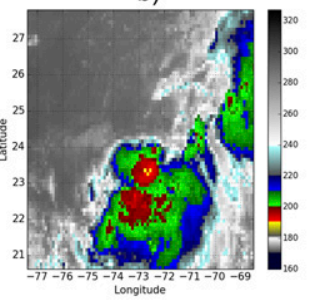

g)

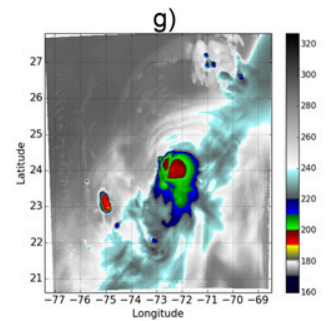

c)

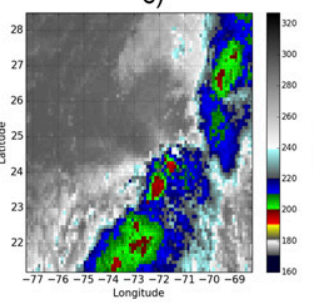

h)

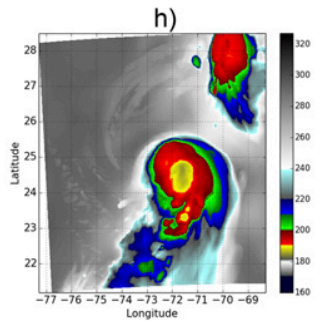

d)

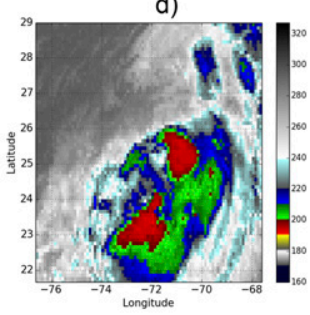

i)

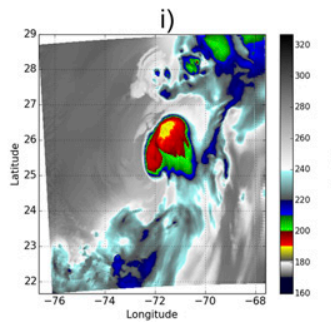

e)
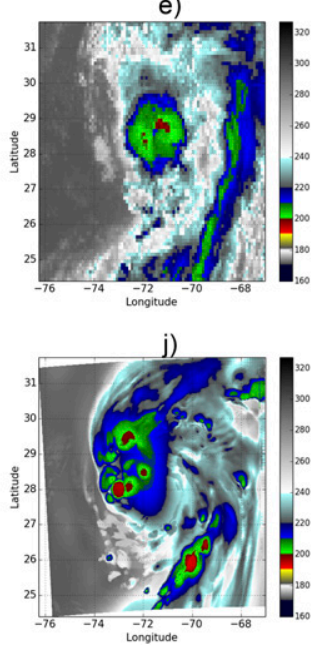

FIG. 11. GOES-13 10.7- $\mu \mathrm{m}$ infrared imagery (brightness temperature in K) valid at (a) 1800 UTC 24 Aug (cycle 2), (b) 0600 UTC 25 Aug (cycle 4), (c) 1800 UTC 25 Aug (cycle 6), (d) 0600 UTC 26 Aug (cycle 8), and (e) 1800 UTC 26 Aug (cycle 10). (f)-(j) As in (a)-(e), but for synthetic satellite images from the corresponding AddATMS_ALLSKY analyses.

first few hours could be considered the so-called spinup period. Similar to Fig. 12a, forecasts initialized from the five cycles when ATMS data were available are used to create the histogram in Figs. 12b-d. During the first $3 \mathrm{~h}$, the AddATMS_CLRSKY case shows fewer cold clouds than observed for temperatures less than approximately $220 \mathrm{~K}$. In contrast, the AddATMS_ALLSKY case produces cold clouds that are supported by observations for temperatures less than $220 \mathrm{~K}$.

One other type of independent observations that can be used is retrieved rain rates (Figs. 13a,d) from hurricane GPROF (Brown et al. 2016; Wu et al. 2016). Since CWM is a prognostic variable for HWRF, as a first step, column-integrated CWM will be interpreted as a proxy for rain rates (Figs. 13b,c and 13e,f) in order to compare with hurricane GPROF-retrieved rain rates. There appears to be a qualitative agreement between the retrieval and forecast fields. However, computation of the correlation of coefficients between the retrieved rain rates and the column-integrated CWM from the AddATMS_CLRSKY (AddATMS_ALLSKY) case resulted in values of $0.018(0.046)$ and $0.027(0.134)$ for those shown in Figs. 13a-c and Figs. 13d-f, respectively. One challenge of such statistics between an observed and simulated variable, in general, is that a spatial shift between the simulated and observed variables will result in low values of correlation coefficients. Notice in particular that the center of the observed storm (Figs. 13a,d), the center in the AddATMS_CLRKY case (Figs. 13b,e), and the center in the AddATMS ALLSKY cases (Figs. 13c,f) are in three different locations.
Finally, the AddATMS_ALLSKY forecasts within the first hour are examined in greater detail. Figure 14 illustrates the forecasts of the first $30 \mathrm{~min}$ from the analysis of the 10th cycle of AddATMS_ALLSKY, which is valid at 1800 UTC 26 August. Because of the absence of vertical motion at the initial time, the value of CWM during the first $5 \mathrm{~min}$ has decreased considerably (Figs. 14a,b). A closer examination is made of the region near $26^{\circ} \mathrm{N}, 73^{\circ} \mathrm{W}$ (black box in Figs. $14 \mathrm{a}, \mathrm{b}$ ) and is displayed in Figs. 14c and 14d. In Fig. 14c, the CWM field (magenta contour) is within a region of downward vertical motion of approximately $-0.5 \mathrm{~m} \mathrm{~s}^{-1}$ (blue dashed contour) and was bounded by upward vertical motion of approximately $0.5 \mathrm{~m} \mathrm{~s}^{-1}$ (red contour). Note in particular that the CWM field and sinking motion are collocated with a localized cold pool approximately $4 \mathrm{~K}$ colder than the near environment (gray shades). Results from Figs. 14a-c suggest CWM values decrease due to evaporation and precipitation settling. To further explore this process, a vertical cross section was made along the black line at $73.2^{\circ} \mathrm{W}$ exhibited in Fig. $14 \mathrm{c}$. A relatively large region of downward motion (blue dashed contour) is collocated with the CWM field (magenta contour) in Fig. 14d. In response to the sinking, divergence of the horizontal component of the winds existed below approximately the 20th model level (color shading in Fig. 14d). Also in response to the sinking and horizontal divergence, convergence and upward vertical motion bounds the CWM field. The combination of (i) evaporative cooling, (ii) sinking and divergence, and (iii) convergence and upward vertical motion highlights the generation of a secondary circulation. One may 
a)
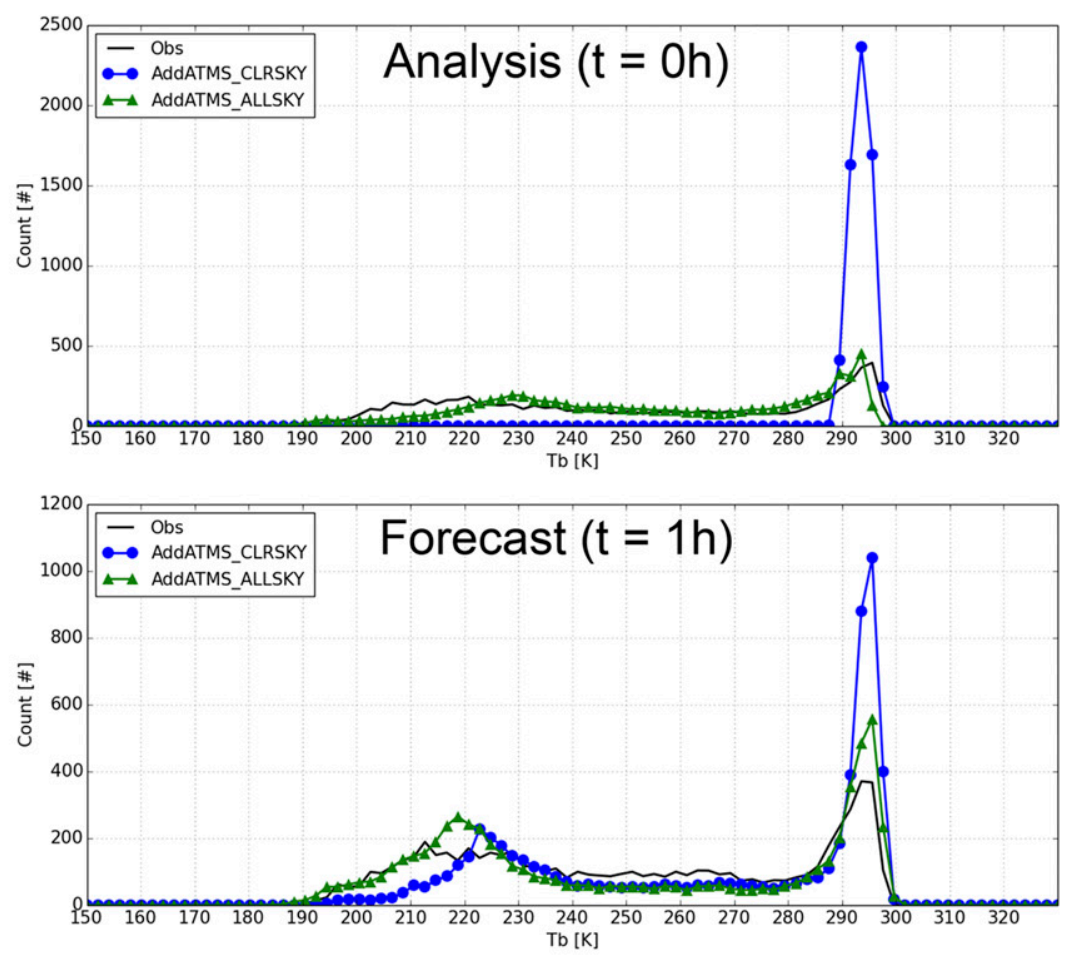

c)
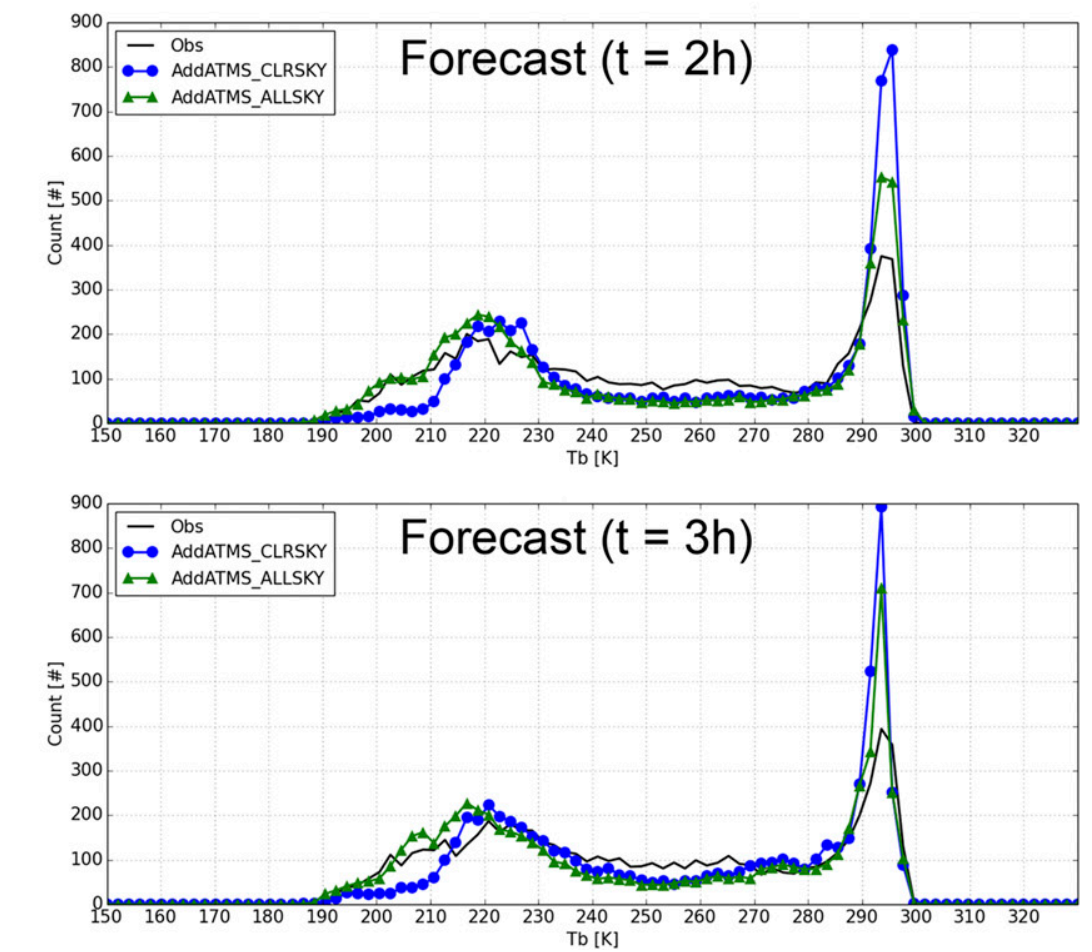

FIG. 12. Histogram of both observed (black) and synthetic (blue: AddATMS_CLRSKY; green: AddATMS_ALLSKY) GOES-13 10.7- $\mu \mathrm{m}$ brightness temperature (K) for (a) analysis, (b) 1-h forecast, (c) 2-h forecast, and (d) 3-h forecast. 

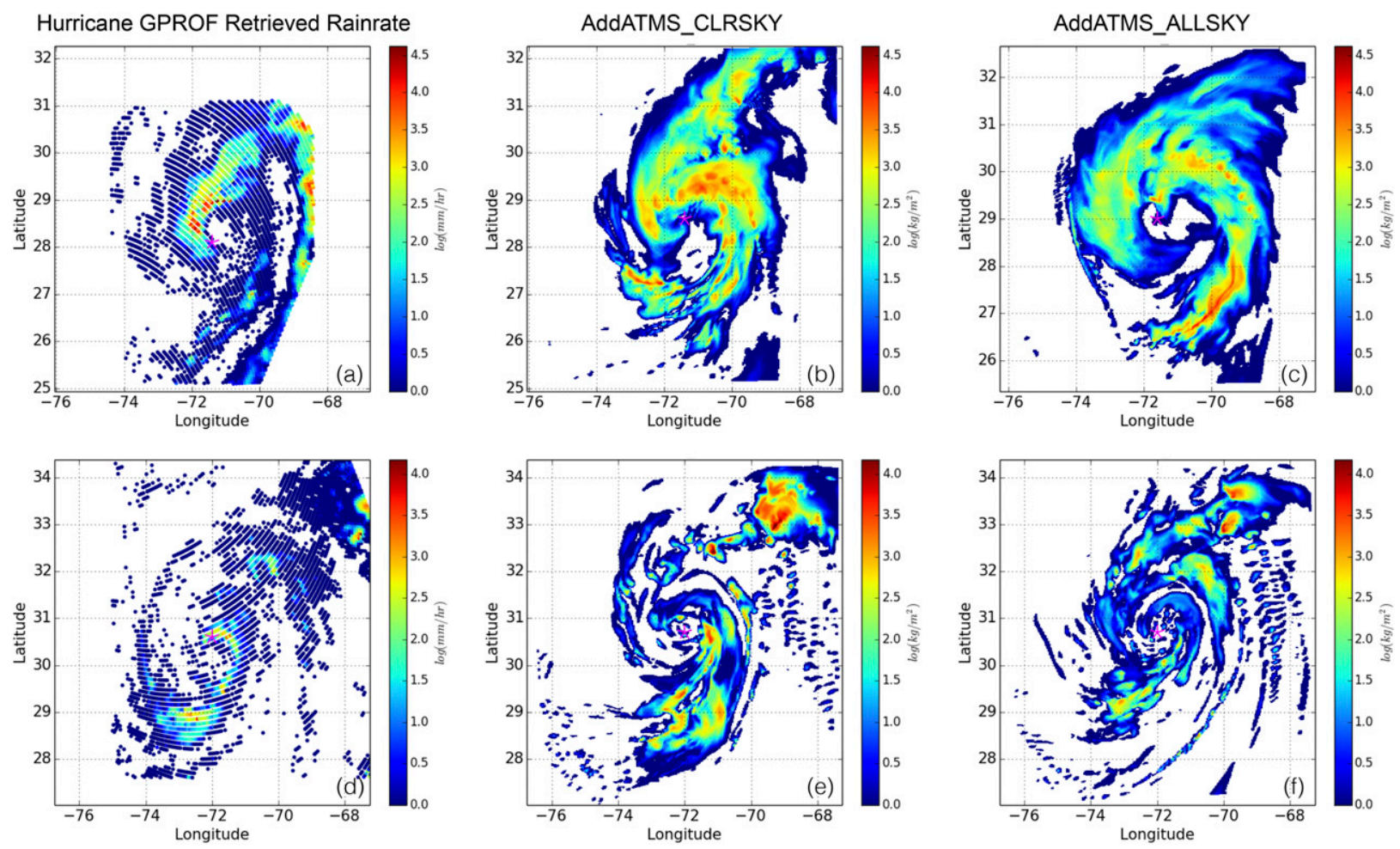

FIG. 13. (a) Hurricane GPROF-retrieved rain rates $\left(\mathrm{mm} \mathrm{h}^{-1}\right.$ in log scale), and column-integrated CWM ( $\mathrm{kg} \mathrm{m}^{-2}$ in log scale) from $12-\mathrm{h}$ HWRF forecasts that are initialized from (b) AddATMS_CLRSKY and (c) AddATMS_ALLSKY analyses at 0600 UTC 26 Aug 2014 (cycle 8). (d)-(f) As in (a)-(c), but for 12-h HWRF forecasts that are initialized from analyses at 1800 UTC 26 Aug 2014 (cycle 10). The unit $\mathrm{kg} \mathrm{m}^{-2}$ is equivalent to mm after dividing by density of liquid water, which is $1000 \mathrm{~kg} \mathrm{~m}^{-3}$.

wonder if the CWM field that was updated via all-sky radiance data assimilation is, in general, settling and evaporating; examination of Figs. 14e and 14f suggests such a process occurred. After $30 \mathrm{~min}, \mathrm{HWRF}$ generated a new CWM field; $1 \mathrm{~h}$ later, the CWM field resulted in synthetic brightness temperatures that were supported by observations (Fig. 12b).

In short, the update of cloud condensates via all-sky radiance assimilation is accompanied by a consistent update of several other prognostic variables. However, due to the current architecture of HWRF, vertical wind is not a prognostic variable. In addition, during the initialization of a forecast, values of the vertical wind are set to zero. One unforeseen consequence is that the CWM field, updated during the assimilation, undergoes evaporation and precipitation settling, followed by HWRF developing a new CWM field. That is, the new CWM field developed by HWRF is independent of the CWM field that was updated by the all-sky radiance assimilation process.

\section{Summary, conclusions, and future direction}

Microwave ocean-only all-sky radiances from ATMS are assimilated into HWRF. Further, the current study benefits from recent developments of Zhu et al. (2016). To extend their global all-sky capability for ocean-only and nonprecipitating clouds to HWRF, several modifications are required. First, code modification is necessary to allow predicted values of both total condensate and partition parameters to be included in the background. Second, following Zhu et al. (2016), total condensate is also added as a control variable for HWRF. The number of hydrometeor state variables was extended to six from two, which was used in the global configuration. As a result, code modification is also necessary in hybrid GSI. Third, in order to include precipitation-affected satellite pixels, quality control within hybrid GSI is modified. Finally, development of a new set of observation errors for cloudy and precipitation-affected ATMS pixels is necessary because they do not exist for the scale of tropical systems (Zhu et al. 2017).

Hurricane Cristobal, which occurred in the 2014 Atlantic hurricane season, is selected as a single case study to demonstrate the methodology of extending global all-sky radiance assimilation capability to HWRF. Two parallel 10-cycle data assimilation experiments are conducted. The AddATMS_CLRSKY experiment follows 
(a)

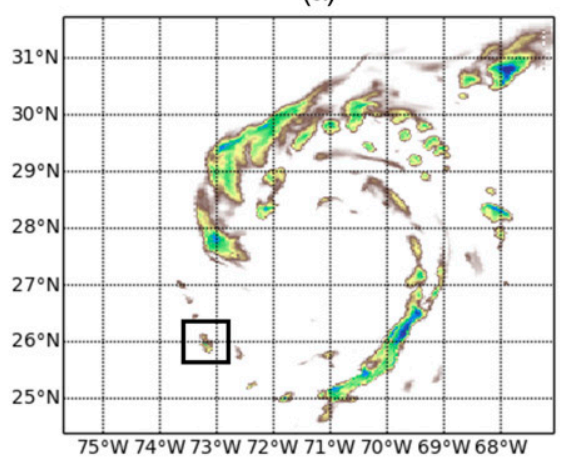

(c)

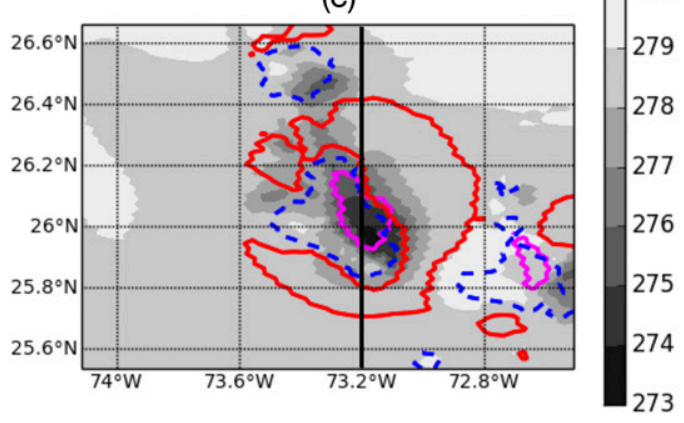

[g/kg]

\section{0}

7.2

$-6.4$

5.6

$-4.8$

4.0

$-3.2$

$-2.4$

$-1.6$

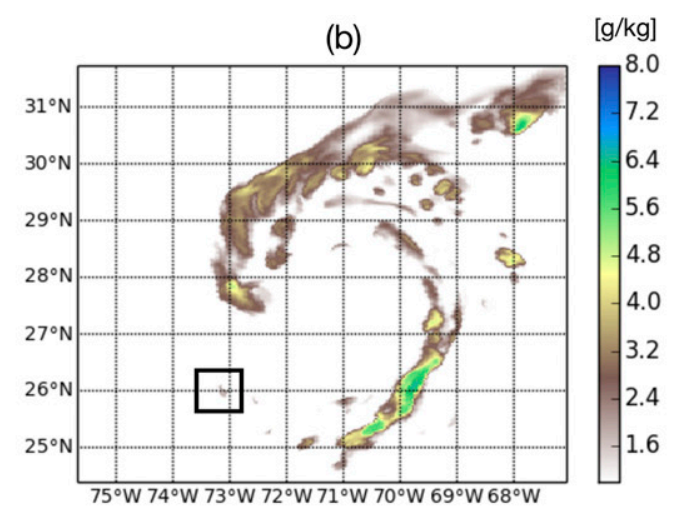

(d)

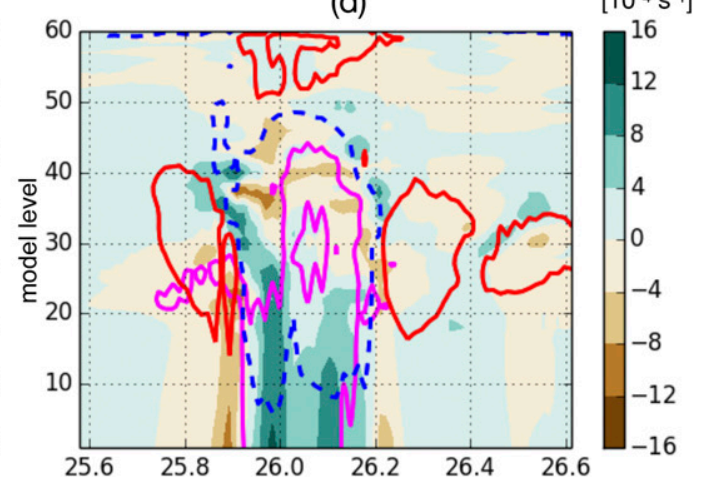

(e)

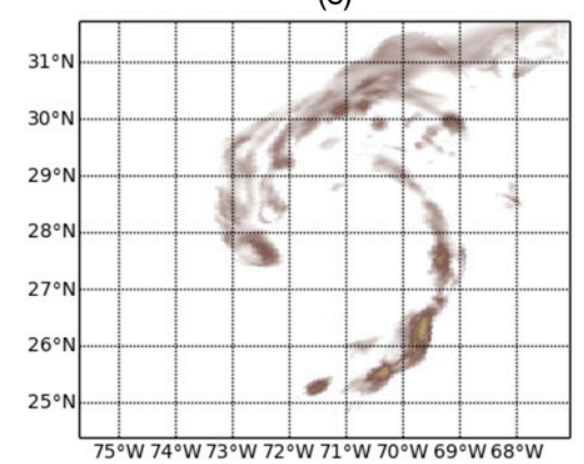

$[\mathrm{g} / \mathrm{kg}]$

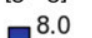

8.0

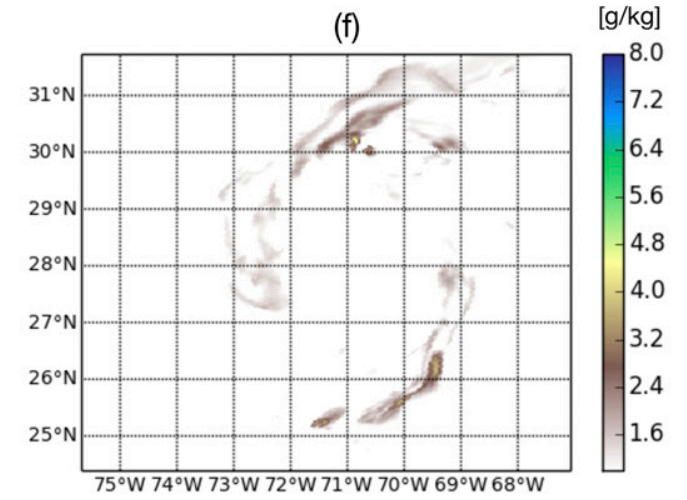

FIG. 14. (a) CWM ( $\mathrm{g} \mathrm{kg}^{-1}$; color) at model level 35 of 0 -h forecast initialized from the AddATMS_ALLSKY analysis that is valid at 1800 UTC 26 Aug 2014 (cycle 10). (b) As in (a), but for 5-min forecast. (c) Enlarged view of the black box in (b) near $26^{\circ} \mathrm{N}, 73^{\circ} \mathrm{W}$. Temperature (K) is plotted in gray shades, CWM with value of $1.0 \mathrm{~g} \mathrm{~kg}^{-1}$ is denoted by magenta contours, and vertical winds with value of $0.5 \mathrm{~m} \mathrm{~s}^{-1}$ are denoted by red contours and vertical winds with value of $-0.5 \mathrm{~m} \mathrm{~s}^{-1}$ are denoted by dashed blue contours. (d) North-south vertical cross section along the black solid line at $73.2^{\circ} \mathrm{W}$ in (c). CWM and vertical winds are plotted using the same conventions as in (c), while horizontal divergence $\left(10^{-4} \mathrm{~s}^{-1}\right)$ is plotted in color shading. (e),(f) As in (b), but for 15- and 30-min forecasts, respectively. 
the 2015 operational HWRF implementation and assimilates clear-sky ATMS radiances from channels 1-4, 7-9, and 16 into ghost-d03 of HWRF. In contrast, the AddATMS_ALLSKY experiment uses all-sky ATMS radiances and modifies the operational configuration to allow all-sky radiance assimilation and cloud microphysical variable updates and cycling.

Results suggest an overall improved fit to observations in the AddATMS_ALSKY experiment, particularly for cloudy and precipitation-affected pixels. However, noticeable biases are still evident, which are likely due to the use of global bias-correction coefficients. In addition, synthetic GOES-13 imagery at $10.7 \mu \mathrm{m}$ and synthetic GMI imagery at $89 \mathrm{GHz}$ of the analyses for both experiments is compared to observed imagery. Results indicate that the AddATMS_ALLSKY experiment has cloud signatures that are comparable to observations. As anticipated, the comparison for the other experiment shows a lack of support by satellite observations due to the absence of clouds in the AddATMS_CLRSKY experiment.

Observed and synthetic GOES-13 satellite data are also used to evaluate HWRF forecasts initialized from the two sets of analyses with the aid of histograms. During the first $3 \mathrm{~h}$ of a forecast, the AddATMS_CLRSKY case exhibits a noticeable lag in the development of cold cloudy pixels. On the other hand, the AddATMS_ALLSKY case maintains cold clouds from the initial time, which are supported by observations. However, due to the absence of upward vertical motion, the CWM field experiences evaporation and precipitation settling.

A few issues are reserved for future work. First, although all-sky radiance assimilation is in the developmental stage, there may be an opportunity to run several data assimilation experiments where each run uses a different microphysical scheme. Results may be used to highlight variations in the three-dimensional structure of condensate within the GSI analysis field. Second, the integrity of optical properties of microphysical habit types needs to be explored, because optical information is the way microphysics is communicated to the CRTM. That is, the innovation is highly dependent on CRTM computed brightness temperatures, which themselves are highly dependent on optical properties. Third, as a result of the deactivation of the blending procedure in HWRF, analysis increments are retained in the core of the innermost domain. Consequently, a potential dynamical imbalance may exist in the inner core of a tropical system. Maintaining a dynamical balance in the analysis field is important for a subsequent forecast. Fourth, since this study is a first step toward all-sky radiance assimilation for HWRF, more experiments are required to develop general conclusions that speak to the all-sky radiance technique herein. Fifth, the current operational HWRF system inherits bias-correction coefficients from GDAS and an ensemble background error covariance that is derived from the GFS ensemble forecasts. Because of the different numerical architectures and length scales between the GFS and the HWRF models, features that are pertinent to a tropical system may not be represented by the GFS. Such inconsistent treatment may be avoided by using data derived directly from HWRF.

Acknowledgments. This research is funded by the NOAA Sandy Supplemental Award NA14OAR4830122, the NOAA GOES-R Risk Reduction Award NA14OAR4320125, and the Hurricane Forecast Improvement Program Award NA18NWS4680059. The assimilation and forecast experiments were performed using the NOAA/ NESDIS Center for Satellite Applications and Research (STAR) "S4" supercomputer located at the University of Wisconsin-Madison. The authors thank Dr. Paula Brown for preparing the Hurricane GPROF retrieved rain rate data for Hurricane Cristobal and Dr. John Knaff for his expert advice on the ATMS channel selection and providing the aircraft-based tropical cyclone surface wind analysis data. The contents in this paper are solely the opinions of the authors and do not constitute a statement of policy, decision, or position on behalf of NOAA or the U.S. government.

\section{REFERENCES}

Aligo, E., B. S. Ferrier, J. Carley, E. Rogers, M. Pyle, S. J. Weiss, and I. L. Jirak, 2014: Modified microphysics for use in highresolution NAM forecasts. 27th Conf. on Severe Local Storms, Madison, WI, Amer. Meteor. Soc., 16A.1, https://ams.confex. com/ams/27SLS/webprogram/Paper255732.html.

Bauer, P., A. J. Geer, P. Lopez, and D. Salmond, 2010: Direct 4D-Var assimilation of all-sky radiances. Part I: Implementation. Quart. J. Roy. Meteor. Soc., 136, 1868-1885, https://doi.org/ 10.1002/qj.659.

— similation at operational NWP centres. Quart. J. Roy. Meteor. Soc., 137, 1934-1951, https://doi.org/10.1002/qj.905.

- - G. Ohring, C. Kummerow, and T. Auligne, 2011b: Assimilating satellite observations of clouds and precipitation into NWP models. Bull. Amer. Meteor. Soc., 92, ES25-ES28, https://doi.org/10.1175/2011BAMS3182.1.

Bikos, D., and Coauthors, 2012: Synthetic satellite imagery for realtime high-resolution model evaluation. Wea. Forecasting, 27, 784-795, https://doi.org/10.1175/WAF-D-11-00130.1.

Brown, P. J., C. D. Kummerow, and D. L. Randel, 2016: Hurricane GPROF: An optimized ocean microwave rainfall retrieval for tropical cyclones. J. Atmos. Oceanic Technol., 33, 1539-1556, https://doi.org/10.1175/JTECH-D-15-0234.1.

Errico, R. M., P. Bauer, and J.-F. Mahfouf, 2007: Issues regarding the assimilation of cloud and precipitation data. J. Atmos. Sci., 64, 3785-3798, https://doi.org/10.1175/2006JAS2044.1.

Geer, A. J., and P. Bauer, 2011: Observation errors in all-sky data assimilation. Quart. J. Roy. Meteor. Soc., 137, 2024-2037, https:// doi.org/10.1002/qj.830. 
- - — , and P. Lopez, 2010: Direct 4D-Var assimilation of allsky radiances. Part II : Assessment. Quart. J. Roy. Meteor. Soc., 136, 1886-1905, https://doi.org/10.1002/qj.681.

—, and Coauthors, 2018: All-sky satellite data assimilation at operational weather forecasting centres. Quart. J. Roy. Meteor. Soc., 144, 1191-1217, https://doi.org/10.1002/qj.3202.

Grasso, L., D. T. Lindsey, K.-S. S. Lim, A. Clark, D. Bikos, and S. R. Dembek, 2014: Evaluation of and suggested improvements to the WSM6 microphysics in WRF-ARW using synthetic and observed GOES-13 imagery. Mon. Wea. Rev., 142, 3635-3650, https://doi.org/10.1175/MWR-D-14-00005.1.

— _ _ - Y.-J. Noh, C. O'Dell, T.-C. Wu, and F. Kong, 2018: Improvements to cloud-top brightness temperatures computed from the CRTM at $3.9 \mu \mathrm{m}$. Mon. Wea. Rev., 146, 39273944, https://doi.org/10.1175/MWR-D-17-0342.1.

Grody, N., J. Zhao, R. Ferraro, F. Weng, and R. Boers, 2001: Determination of precipitable water and cloud liquid water over oceans from the NOAA 15 advanced microwave sounding unit. J. Geophys. Res., 106, 2943-2953, https:// doi.org/10.1029/2000JD900616.

Guerbette, J., J. F. Mahfouf, and M. Plu, 2016: Towards the assimilation of all-sky microwave radiances from the SAPHIR humidity sounder in a limited area NWP model over tropical regions. Tellus, 68A, 28620, https://doi.org/10.3402/ tellusa.v68.28620.

Guidard, V., N. Fourrié, P. Brousseau, and F. Rabier, 2011: Impact of IASI assimilation at global and convective scales and challenges for the assimilation of cloudy scenes. Quart. J. Roy. Meteor. Soc., 137, 1975-1987, https://doi.org/10.1002/qj.928.

Han, Y., P. van Delst, Q. Liu, F. Weng, B. Yan, R. Treadon, and J. Derber, 2006: JCSDA Community Radiative Transfer Model (CRTM) - version 1. NOAA Tech. Rep. NESDIS 122, 40 pp., https://repository.library.noaa.gov/view/noaa/1157.

Heilliette, S., and L. Garand, 2007: A practical approach for the assimilation of cloudy infrared radiances and its evaluation using airs simulated observations. Atmos.-Ocean, 45, 211-225, https://doi.org/10.3137/ao.450403.

_ Y. J. Rochon, L. Garand, and J. W. Kaminski, 2013: Assimilation of infrared radiances in the context of observing system simulation experiments. J. Appl. Meteor. Climatol., 52, 1031-1045, https://doi.org/10.1175/JAMC-D-12-0124.1.

Huang, X. Y., 1996: Initialization of cloud water content in a data assimilation system. Mon. Wea. Rev., 124, 478-486, https:// doi.org/10.1175/1520-0493(1996)124<0478:IOCWCI>2.0.CO;2.

Janjic, Z. I., 2003: A nonhydrostatic model based on a new approach. Meteor. Atmos. Phys., 82, 271-285, https://doi.org/ 10.1007/s00703-001-0587-6.

Kleist, D. T., and K. Ide, 2015: An OSSE-based evaluation of hybrid variational-ensemble data assimilation for the NCEP GFS. Part II: 4DEnVar and hybrid variants. Mon. Wea. Rev., 143, 452-470, https://doi.org/10.1175/MWR-D-13-00350.1.

- D. F. Parrish, J. C. Derber, R. Treadon, W.-S. Wu, and S. Lord, 2009: Introduction of the GSI into the NCEP Global Data Assimilation System. Wea. Forecasting, 24, 1691-1705, https://doi.org/10.1175/2009WAF2222201.1.

Lu, X., X. Wang, M. Tong, and V. Tallapragada, 2017: GSI-based, continuously cycled, dual-resolution hybrid ensemblevariational data assimilation system for HWRF: System description and experiments with Edouard (2014). Mon. Wea. Rev., 145, 4877-4898, https://doi.org/10.1175/MWR-D-170068.1.

Marchok, T. P., 2002: How the NCEP tropical cyclone tracker works. 25th Conf. on Hurricanes and Tropical Meteorology,
San Diego, CA, Amer. Meteor. Soc., P1.13, https://ams. confex.com/ams/25HURR/techprogram/paper_37628.htm.

Minamide, M., and F. Zhang, 2017: Adaptive observation error inflation for assimilating all-sky satellite radiance. Mon. Wea. Rev., 145, 1063-1081, https://doi.org/10.1175/MWR-D-16-0257.1. , and — 2018: Assimilation of all-sky infrared radiances from Himawari- 8 and impacts of moisture and hydrometer initialization on convection-permitting tropical cyclone prediction. Mon. Wea. Rev., 146, 3241-3258, https://doi.org/10.1175/ MWR-D-17-0367.1.

Okamoto, K., 2013: Assimilation of overcast cloudy infrared radiances of the geostationary MTSAT-1R imager. Quart. J. Roy. Meteor. Soc., 139, 715-730, https://doi.org/10.1002/qj.1994.

Parrish, D. F., and J. C. Derber, 1992: The National Meteorological Center's spectral statistical-interpolation analysis system. Mon. Wea. Rev., 120, 1747-1763, https://doi.org/10.1175/15200493(1992)120<1747:TNMCSS $>2.0$. CO;2.

$\mathrm{Pu}, \mathrm{Z}$., S. Zhang, M. Tong, and V. Tallapragada, 2016: Influence of the self-consistent regional ensemble background error covariance on hurricane inner-core data assimilation with the GSI-based hybrid system for HWRF. J. Atmos. Sci., 73, 4911-4925, https://doi.org/10.1175/JAS-D-16-0017.1.

Renshaw, R., and P. N. Francis, 2011: Variational assimilation of cloud fraction in the operational Met Office Unified Model. Quart. J. Roy. Meteor. Soc., 137, 1963-1974, https://doi.org/ 10.1002/qj.980.

Tallapragada, V., and Coauthors, 2015: Hurricane Weather Research and Forecasting (HWRF) Model: 2015 scientific documentation. NCAR Tech. Note NCAR/TN-522+STR, 122 pp., https://doi.org/10.5065/D6ZP44B5.

Wang, X., 2010: Incorporating ensemble covariance in the gridpoint statistical interpolation variational minimization: A mathematical framework. Mon. Wea. Rev., 138, 2990-2995, https://doi.org/10.1175/2010MWR3245.1.

, and T. Lei, 2014: GSI-based four-dimensional ensemblevariational (4DEnsVar) data assimilation: Formulation and single-resolution experiments with real data for NCEP Global Forecast System. Mon. Wea. Rev., 142, 3303-3325, https:// doi.org/10.1175/MWR-D-13-00303.1.

_ D. Parrish, D. Kleist, and J. Whitaker, 2013: GSI 3DVarbased ensemble-variational hybrid data assimilation for NCEP Global Forecast System: Single-resolution experiments. Mon. Wea. Rev., 141, 4098-4117, https://doi.org/10.1175/MWR-D-1200141.1

Weng, F., 2007: Advances in radiative transfer modeling in support of satellite data assimilation. J. Atmos. Sci., 64, 3799-3807, https://doi.org/10.1175/2007JAS2112.1.

— weather prediction models. Part I: Forward radiative transfer and Jacobian modeling in cloudy atmospheres. J. Atmos. Sci., 60, 2633-2646, https://doi.org/10.1175/1520-0469(2003) $060<2633:$ SDAINW $>2.0$. CO 2 .

Wu, T.-C., and M. Zupanski, 2017: Assimilating GPM hydrometeor retrievals in HWRF: Choice of observation operators. Atmos. Sci. Lett., 18, 238-245, https://doi.org/10.1002/asl.748.

,-- L. D. Grasso, P. J. Brown, C. D. Kummerow, and J. A. Knaff, 2016: The GSI capability to assimilate TRMM and GPM hydrometeor retrievals in HWRF. Quart. J. Roy. Meteor. Soc., 142, 2768-2787, https://doi.org/10.1002/qj.2867.

Wu, W.-S., R. J. Purser, and D. F. Parrish, 2002: Three-dimensional variational analysis with spatially inhomogeneous covariances. Mon. Wea. Rev., 130, 2905-2916, https://doi.org/10.1175/15200493(2002)130<2905:TDVAWS > 2.0.CO;2. 
Yablonsky, R. M., I. Ginis, B. Thomas, V. Tallapragada, D. Sheinin, and L. Bernardet, 2015: Description and analysis of the ocean component of NOAA's operational Hurricane Weather Research and Forecasting Model (HWRF). J. Atmos. Oceanic Technol., 32, 144-163, https://doi.org/10.1175/JTECH-D14-00063.1.

Yang, C., Z. Liu, J. Bresch, S. R. H. Rizvi, X. Y. Huang, and J. Min, 2016: AMSR2 all-sky radiance assimilation and its impact on the analysis and forecast of Hurricane Sandy with a limitedarea data assimilation system. Tellus, 68A, 30917, https:// doi.org/10.3402/tellusa.v68.30917.

Zhang, F., M. Minamide, and E. E. Clothiaux, 2016: Potential impacts of assimilating all-sky infrared satellite radiances from GOES-R on convection-permitting analysis and prediction of tropical cyclones. Geophys. Res. Lett., 43, 2954-2963, https:// doi.org/10.1002/2016GL068468.

Zhang, M., M. Zupanski, M.-J. Kim, and J. A. Knaff, 2013: Assimilating AMSU-A radiances in the TC core area with NOAA operational HWRF (2011) and a hybrid data assimilation system: Danielle (2010). Mon. Wea. Rev., 141, 38893907, https://doi.org/10.1175/MWR-D-12-00340.1.

Zhu, Y., J. Derber, A. Collard, D. Dee, R. Treadon, G. Gayno, and J. A. Jung, 2014: Enhanced radiance bias correction in the
National Centers for Environmental Prediction's Gridpoint Statistical Interpolation data assimilation system. Quart. J. Roy. Meteor. Soc., 140, 1479-1492, https://doi.org/10.1002/ qj.2233.

__ , and Coauthors, 2016: All-sky microwave radiance assimilation in NCEP's GSI analysis system. Mon. Wea. Rev., 144, 4709-4735, https://doi.org/10.1175/MWR-D-15-0445.1.

_ , and Coauthors, 2017: Further development in the all-sky microwave radiance assimilation and expansion to ATMS in the GSI at NCEP. Proc. 21st Int. TOVS Study Conf., Damstadt, Germany, International TOVS Working Group, $11 \mathrm{pp}$.

Zou, X., F. Weng, B. Zhang, L. Lin, Z. Qin, and V. Tallapragada, 2013: Impacts of assimilation of ATMS data in HWRF on track and intensity forecasts of 2012 four landfall hurricanes. J. Geophys. Res. Atmos., 118, 11 558-11 576, https://doi.org/ 10.1002/2013JD020405.

Zupanski, M., 2005: Maximum likelihood ensemble filter: Theoretical aspects. Mon. Wea. Rev., 133, 1710-1726, https:// doi.org/10.1175/MWR2946.1.

_ 2013: All-sky satellite radiance data assimilation: Methodology and Challenges. Data Assimilation for Atmospheric, Oceanic and Hydrologic Applications (Vol. II), S.-K. Park and L. Xu, Eds., Springer, 465-488. 